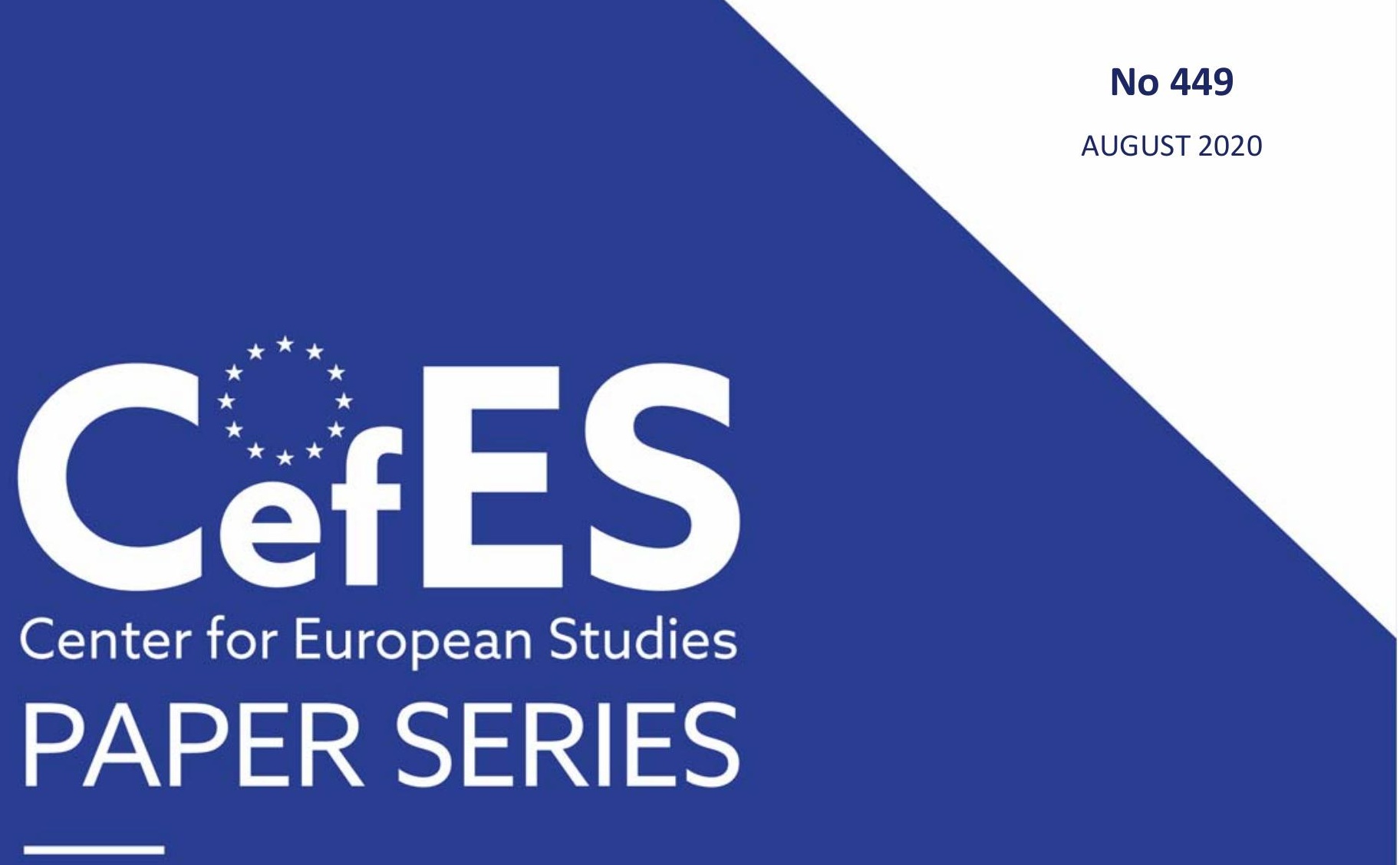

\title{
Exposure to ethnic minorities changes attitudes to them
}

Sabina Albrecht, Riccardo Ghidoni, Elena Cettolin and Sigrid Suetens 


\title{
Exposure to ethnic minorities changes attitudes to them
}

\author{
Sabina Albrecht \\ Queensland University of Technology, School of Economics and Finance, \\ e-mail: sabina.albrecht@qut.edu.au \\ Riccardo Ghidoni \\ University of Milano-Bicocca, CefES, Department of Economics, Management and Statistics, \\ e-mail: riccardo.ghidoni@unimib.it \\ Elena Cettolin \\ Tilburg University, CentER, Department of Economics, \\ e-mail: e.cettolin@uvt.nl \\ Sigrid Suetens ${ }^{1}$ \\ Tilburg University, CentER, Department of Economics, \\ e-mail: s.suetens@uvt.nl
}

August 26, 2020

\begin{abstract}
Does exposure to ethnic minorities change the majority's attitudes towards them? We investigate this question using novel panel data on attitudes from a general-population sample in the Netherlands matched to geographical data on refugees. We find that people who live in neighborhoods of refugees for a sufficiently long time acquire a more positive attitude. Instead, people living in municipalities hosting refugees, but not in their close neighborhood, develop a more negative attitude. The positive neighborhood effect is particularly strong for groups that are likely to have personal contact with refugees suggesting that contact with minorities can effectively reduce prejudice.
\end{abstract}

JEL Codes: J15, R23, D91, C23

Keywords: prejudice, ethnic diversity, attitudes to immigrants, discrimination, intergroup contact, refugee crisis, individual-level fixed-effects regressions, lab-in-the-field experiment

\footnotetext{
${ }^{1}$ Corresponding author. We are also indebted to audiences of seminars at the universities of Amsterdam, Göteborg, Milano-Bicocca, Queensland, Regensburg, Stavanger, Tilburg, Würzburg, the Norwegian School of Economics (FAIR), the European University Institute and the Melbourne Institute, as well as attendees at the Labour Econometrics Workshop 2019 for insightful comments. Suetens acknowledges financial support from the European Commission (ERC Consolidator Grant, grant number 724231).
} 


\section{Introduction}

Ethnic minorities do not always fare well in Western countries and are often confronted with negative stereotypes and prejudice. For example, they are less frequently invited for job interviews than majority applicants with an equivalent curriculum vitae (Bertrand and Mullainathan, 2004; Heath, Liebig, and Simon, 2013), earn a lower wage due to prejudice (Charles and Guryan, 2008), are less frequently hired than equally productive majority workers (Hedegaard and Tyran, 2018), and face racial bias in court (Shayo and Zussman, 2011; Anwar, Bayer, and Hjalmarsson, 2012) and in trade (List, 2004; Ayres, Banaji, and Jolls, 2015). In recent decades, migration waves and demographic evolutions have led to an increased presence of ethnic minorities in Western countries, and this trend is expected to continue in the near future (de la Rica, Glitz, and Ortega, 2015; Hanson and McIntosh, 2016). It is an open question whether an increased presence of minorities improves or worsens the majority's attitudes to them. ${ }^{1}$ Persistent prejudices can lead to a socio-economic divide and ultimately to conflicts between majority and minority groups. It is thus crucial to understand how attitudes towards ethnic minorities change in response to their increased presence.

In this paper we combine administrative data on the location of refugee centers in the Netherlands with panel data on the residencies of locals and their attitudes towards ethnic diversity in society. ${ }^{2}$ In the period of study, 2011-2016, the country has been exposed to a large inflow of refugees during what has been called the European refugee crisis. In 2015 the number of refugees and centers almost tripled as compared to the previous years, and this increase was largely unanticipated. The data provide the opportunity for the first time to identify how

\footnotetext{
${ }^{1}$ On the one hand, attitudes are more likely to develop positively if increased exposure leads to the acquisition of information that overcomes negative stereotypes (Phelps, 1972; Arrow, 1973), or if it makes people pay more attention to such information (Bartoš, Bauer, Chytilová, and Matějka, 2016). A positive effect is also more likely if exposure entails positive personal interethnic contact and leads to a common humanity (Allport, 1954). On the other hand, fears for an increase in labor market competition (Ortega and Polavieja, 2012), for a change in cultural norms (Card, Dustmann, and Preston, 2012), or for a decay in the welfare state (Dustmann and Preston, 2007) may prevent the development of common goals and social norms. Several studies establish a negative effect of ethnic diversity on collective action or redistribution (Alesina and La Ferrara, 2005; Dahlberg, Edmark, and Lundqvist, 2012; Algan, Hémet, and Laitin, 2016). Tabellini (2020) shows this holds especially when the cultural distance between natives and immigrants is large.

${ }^{2}$ As in other Western countries, the share of citizens with a different ethnic background has substantially increased in the Netherlands in the last decades. To illustrate, according to the Dutch Central Bureau for Statistics the share of citizens with an immigrant background (i.e. born abroad or with at least one parent born abroad) has increased from 17.5 to 23.6 percent between 2000 and 2019 in the Netherlands, and most of this change can be attributed to an increase in the number of residents with non-Western origins (from 8.9 to 13.4 percent). About 50 percent of the citizens with a non-Western immigrant background have Middle Eastern origins, and about 70 percent were born or have a parent born in a predominantly Muslim country.
} 
individuals of the general population change their attitudes towards ethnic minorities in reaction to increased exposure to them. A key advantage is that thanks to the micro-nature of the data we can account for unobservable differences between individuals. Moreover, we can infer whether individuals react differently depending on how long the refugees stay and depending on whether they reside in the same neighborhood or are instead located further away. This combined with the availability of individual background information helps to explore channels through which the effect operates.

We find that locals who live in the neighborhood of a refugee center develop a more positive attitude towards ethnic diversity, in particular if exposure lasts at least half a year. ${ }^{3}$ The effect then corresponds to about 34 percent of a standard deviation. It is strongest among women, relatively young people, or people with children living at home. If we focus on the presence of refugees in the wider municipality, we instead obtain negative effects. To illustrate, we find that attitudes to ethnic diversity of locals who live in a municipality with a refugee center but not in the center's neighborhood worsen by 10.4 percent of a standard deviation. The negative effect is even stronger, corresponding to 13.8 percent of a standard deviation, if the exposure lasts less than half a year at the point of the attitudes measurement. Given that locals and refugees are more likely to meet (e.g. at the local groceries, at the school gate, etc.) when they live in the same neighborhood than when they do not, we attribute the difference in neighborhood and municipal effects to a difference in likelihood of personal contact. The negative municipal effect cannot stem from frequent personal contact but must instead be driven by other factors such as other forms of awareness (e.g. hearsay, newspapers) or by sharing a common administrative jurisdiction with the refugees. ${ }^{4}$ In summary, our results show that in cases in which scope for personal contact is highest, the presence of ethnic minorities has a positive effect on attitudes towards them.

Our empirical strategy builds upon the assumption that attitudes to ethnic diversity of locals who were not exposed to refugees in their neighborhood or municipality follow the same pattern as attitudes of exposed locals, had exposure not taken place. We report the results of

\footnotetext{
${ }^{3}$ Half a year is about the median length of stay.

${ }^{4}$ Municipalities are on average composed of about 12 postcode neighborhoods and constitute the lowest level of government in the Netherlands. They are responsible for several public services and amenities such as the provision of social housing, local infrastructure, land, water and waste management, school buildings and the environment. Although municipalities with a refugee center receive financial compensation from the government, the opening of a center may (be perceived to) create extra costs to the municipality's finances and change the composition of other services delivered.
} 
several analyses that support the plausibility of this assumption. We show that in years that exposed individuals are not exposed yet, the pattern of their attitudes is not significantly different from that of non-exposed individuals. We also show that results are robust to redefining the control group and do not not hinge on the precise definitions of independent and dependent variables or on particular sample restrictions. Moreover, we produce distributions of counterfactual estimates by randomly reassigning the values of the exposure variables among individuals in our sample to illustrate that results are not due to chance. Finally, if we run the same regressions with other dependent variables that are related to norms in society but that can plausibly be expected to be unaffected by the presence of refugees in the neighborhood, we find only small and non-significant effects.

In order to demonstrate that our dependent variable is behaviorally meaningful, we report the results of a lab-in-the-field experiment in which we used monetary incentives to elicit a measure for ethnic discrimination. The experiment was run on a subset of panelists from the main attitudes estimation sample, and the main finding is that exposure to refugees has a positive effect on this behavioral measure as well. Although the sample is too selective to allow a generalization of the estimated effects, the finding suggests that patterns in data on self-reported attitudes to ethnic diversity provide meaningful information about how ethnic minorities are treated in society as compared to native locals.

Studies that investigate the effect of exposure to minorities on attitudes towards them are typically conducted with specific groups of the population, such as students or military trainees, and it is not all that clear whether results carry over to the general population. Identification strategies typically build upon the random assignment of roommates during an educational or military program. For instance, Boisjoly et al. (2006), Carrell, Hoekstra, and West (2019), and Merlino, Steinhardt, and Wren-Lewis (2019) find that white students at schools in the US who were assigned black roommates in their first year of study are more likely to have inter-ethnic contacts and relationships in later years, and less likely to hold stereotyped beliefs. ${ }^{5}$ Finseraas et al. (2019) and Finseraas and Kotsadam (2017) find that native Norwegian soldiers who are randomly exposed to soldiers from ethnic minorities trust immigrants more, and have more positive views on immigrants' work ethics. ${ }^{6}$ Our paper contributes to this lit-

\footnotetext{
${ }^{5}$ Similar results are found by Corno, La Ferrara, and Burns (2019) in the context of a large South-African university. See also Rao (2019), for a study on the effect of exposure to poor classmates in Indian schools on discrimination against the poor by rich students.

${ }^{6}$ Also related is the study by Albrecht and Smerdon (2019), which looks at the effect of an unexpected inflow of
} 
erature by providing evidence on the effect of exposure to minorities on attitudes for a sample of individuals from the general population.

One study that investigates the effect of exposure to minorities on attitudes towards them using a broadly construed sample is that of Schindler and Westcott (2020). The authors show that in areas in the UK in which African-American soldiers were stationed during World War II, individuals are nowadays less likely to be a member of or vote for the far-right British National Party and are less prejudiced against black. They suggest that first-hand experiences and personal contact with blacks have improved attitudes towards them back then, and that attitudes are transmitted across generations. Although the study employs a large sample, evidence for the causal effect of exposure to minorities on attitudes towards them is indirect and relies on inter-generational transmission. Our study instead provides direct evidence.

Finally, we contribute to a body of work that investigates the effect of exposure to ethnic minorities on voting for far-right, anti-immigrant parties using data on the location of minorities. Identification strategies, samples, and time periods vary across the studies, and results are mixed. ${ }^{7}$ We focus on one of the many possible motivations behind voting behavior, namely attitudes towards ethnic minorities. It is difficult to identify whether effects of exposure to ethnic minorities on voting are due to changes in attitudes to ethnic diversity due to increased exposure or to changes in other factors that are correlated with increased exposure. For example, in the specific context of Europe and the EU, voting for far-right parties may be driven by anti-EU feelings that may stem from a dissatisfaction with how the EU has dealt with the refugee crisis, rather than from negative attitudes towards ethnic diversity per se. Moreover, even if attitudes to ethnic diversity would map directly into voting behavior, it is not clear how the mapping function would look like. Finally, in contrast to voting data, which are typically

refugees in a rural town in Australia on inter-ethnic trust and attitudes towards refugee settlement. The authors find that inter-ethnic trust (by women) increases, and that attitudes towards refugee settlement improve as compared to control towns.

${ }^{7}$ Barone et al. (2016), Halla, Wagner, and Zweimueller (2017), and Edo et al. (2019) use historic settlement patterns of immigrants as an instrument for current immigrant presence and report that in municipalities with an increased presence of immigrants the vote share of the far-right increases in Italy, Austria, and France, respectively. Dustmann, Vasiljeva, and Damm (2019) exploit a quasi-random refugee settlement policy that was implemented in Denmark in 1986-1998, and find that the presence of refugees increases voting for far-right parties in most but the most urbanized municipalities. An opposite effect is found by Calderon, Fouka, and Tabellini (2020), who report a positive effect of exposure to African Americans in 1940-1970 on support by whites for the Democratic Party in the US. If we focus on studies exploiting the 2015 refugee shock, Steinmayr (2020) and Vertier and Viskanic (2018) find that the vote share of the far-right in national elections in Austria and France has overall decreased in municipalities with relatively more refugees. In contrast, Dinas et al. (2019) and Vasilakis (2018) find that in elections that took place in September 2015 in Greece, more people voted for the far-right Golden Dawn on islands and municipalities with the strongest presence of refugees. 
available at an aggregate level only, the disaggregated nature of our data allows to identify effects that are difficult to detect at a more aggregate level. In particular, the nature of our data allows controlling for individual fixed effects and composition effects due to individuals moving to another neighborhood, and allows studying whether different levels of aggregation (neighborhood versus municipality) give different results.

\section{The data}

We use data from three sources. The first source is the Central Agency for the Reception of Asylum Seekers (COA), an organization responsible for the reception and supervision of asylum seekers during the asylum process. The data set provided by COA includes the opening and closing dates of the refugee centers, the location of the centers, and the monthly number of asylum seekers in each center for the period January 2011 to December 2016. The second data source is the Longitudinal Internet Studies for the Social sciences panel (LISS panel), which is an online panel data set on Dutch citizens, managed by CentERdata, a survey research institute located at the campus of Tilburg University. The panel consists of about 7000 individuals from 4500 households, and is based on a true probability sample of households drawn from the population register of Statistics Netherlands. ${ }^{8}$ From the LISS panel we use yearly data on self-reported attitudes to ethnic diversity, several individual-level background variables and the four-digit postcode of the panelists' place of residence. A third data source is Statistics Netherlands (CBS), which publishes yearly socio-demographic register data on municipalities and four-digit postcodes. The different data sets are matched on the basis of the year and the four-digit postcode. ${ }^{9}$ In what follows we first provide information on refugees in the Netherlands and the role of $\mathrm{COA}$, and then provide a detailed account of our main estimation sample.

\subsection{COA and refugees in the Netherlands}

COA is responsible for the reception and supervision of asylum seekers, and it assists those who have been granted asylum with finding accommodation. Asylum seekers who arrive in

\footnotetext{
${ }^{8}$ Households that have no internet connection are provided with the necessary technology that allows them to participate through their television.

${ }^{9}$ To safeguard the privacy of LISS panelists, CentERdata made the complete data set available to us for analysis via remote access. The LISS data are publicly available in a format that does not include information about the four-digit postcode of the place of residence.
} 
the Netherlands register at a central reception center and typically stay there for at most two weeks before they are assigned to one of the many refugee centers in the country. The centers are typically located in or nearby residential areas. A legal requirement is that public transport is within $500 \mathrm{~m}$ reach and schools and stores are within $3 \mathrm{~km}$ reach. During the first six months of waiting for a decision on their status, refugees are not allowed to do paid work, but may participate in voluntary work. After six months they can work for up to twenty-four weeks per year. Refugees receive weekly pocket money to buy groceries and other necessities if they do not have the means to provide for themselves, and are insured for basic health care through the Dutch system. Any money earned through work is deducted from the weekly allowance. At the centers refugees learn about basic Dutch rules and cultural aspects and commence a language course. Children attend local schools, play sports and learn to ride a bicycle. ${ }^{10}$

There is always a certain number of active centers, but the total number varies at any given point in time based on the expected or actual need for accommodation of refugees. Figure 1 shows the development of the number of refugees who reside in centers over time. At the beginning of 2011 less than 20'000 refugees were waiting for the government's decision on their status in one of 48 centers in the country. Over the years 2012 and 2013 the number of refugees in the Netherlands decreased to less than $15^{\prime} 000$ spread over 35 centers, which was due to a reduced inflow and the processing of the existing applications. Mid 2014 saw the first impact of the Syrian civil war and a return to about 50 active refugee centers. One year later, in September 2015, what is sometimes termed the European refugee crisis set in, and the number of refugees rose greatly. As can be seen in Figure 1 the number of refugees living in the Netherlands tripled compared to the beginning of 2014, mostly because of the large inflow from the Middle East. At the peak of the crisis COA operated around 120 centers in the country. Figure 2 shows that the newly arrived refugees were spread over the country.

COA's decision to open a new center, to adjust the size of an existing center or to close one, mainly depends on the demand for refugee accommodation, but the where and when of the decision are influenced by certain guiding principles and other actors. Following Dutch legislation, it is COA's explicit policy to aim for an even spread of refugees over the country, to share the burden and facilitate integration. In addition to that, decisions by COA are made on the basis of the flexibility, sustainability and quality that a particular center offers, and are influenced as

\footnotetext{
${ }^{10}$ Detailed information about the asylum process in the Netherlands can be found on https://www.coa.nl/and https://ind.nl/en/asylum/Pages/Asylum-seeker.aspx.
} 


\section{Figure 1: Number of refugees and centers}

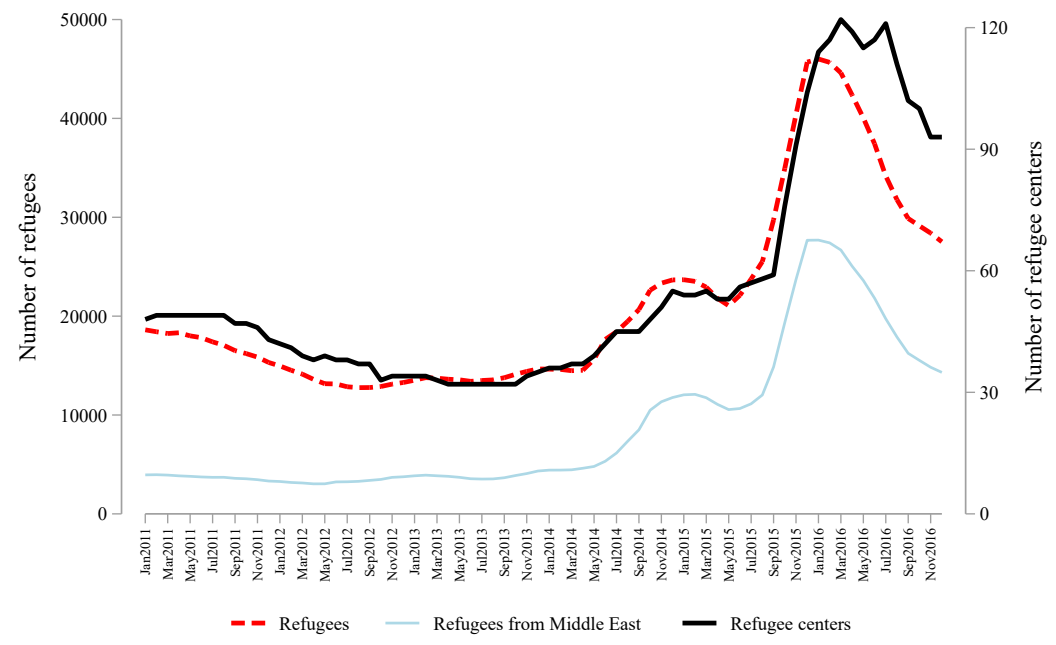

Notes: The figure shows the number of asylum seekers residing in refugee centers (left axis) and the number of refugee centers (right axis) in the Netherlands between January 2011 and December 2016.

well by financial considerations. Besides these guiding principles, the municipality in which a refugee center is (to be) located has its say in the decision process and its influence varies from case to case. In some cases, the availability of vacant government property such as former prisons or fallow private land have led to the creation of a refugee center in a particular municipality. In most cases, however, the local council enters a contract with COA allowing to operate a refugee center on municipality premises. This implies that the local residents' attitudes to refugees may influence whether a center would be located in their municipality, and possibly how long it remains open. We elaborate more on this point when we discuss our identification strategy in Section 3.

\subsection{Main estimation sample}

Our main estimation sample covers the period 2011-2016. We focus on comparing panelists who have experienced the opening of a center in their neighborhood to panelists who did not have this experience. More precisely, the panelists in our sample either did not have a refugee center in their postcode from 2011 onwards and several years before 2011 (i.e. the control group), or live in a postcode in which a refugee center has opened between 2011 and 2016, and remained open up until the time of measurement. For identification purposes, we did not 
Figure 2: Refugees in the Netherlands
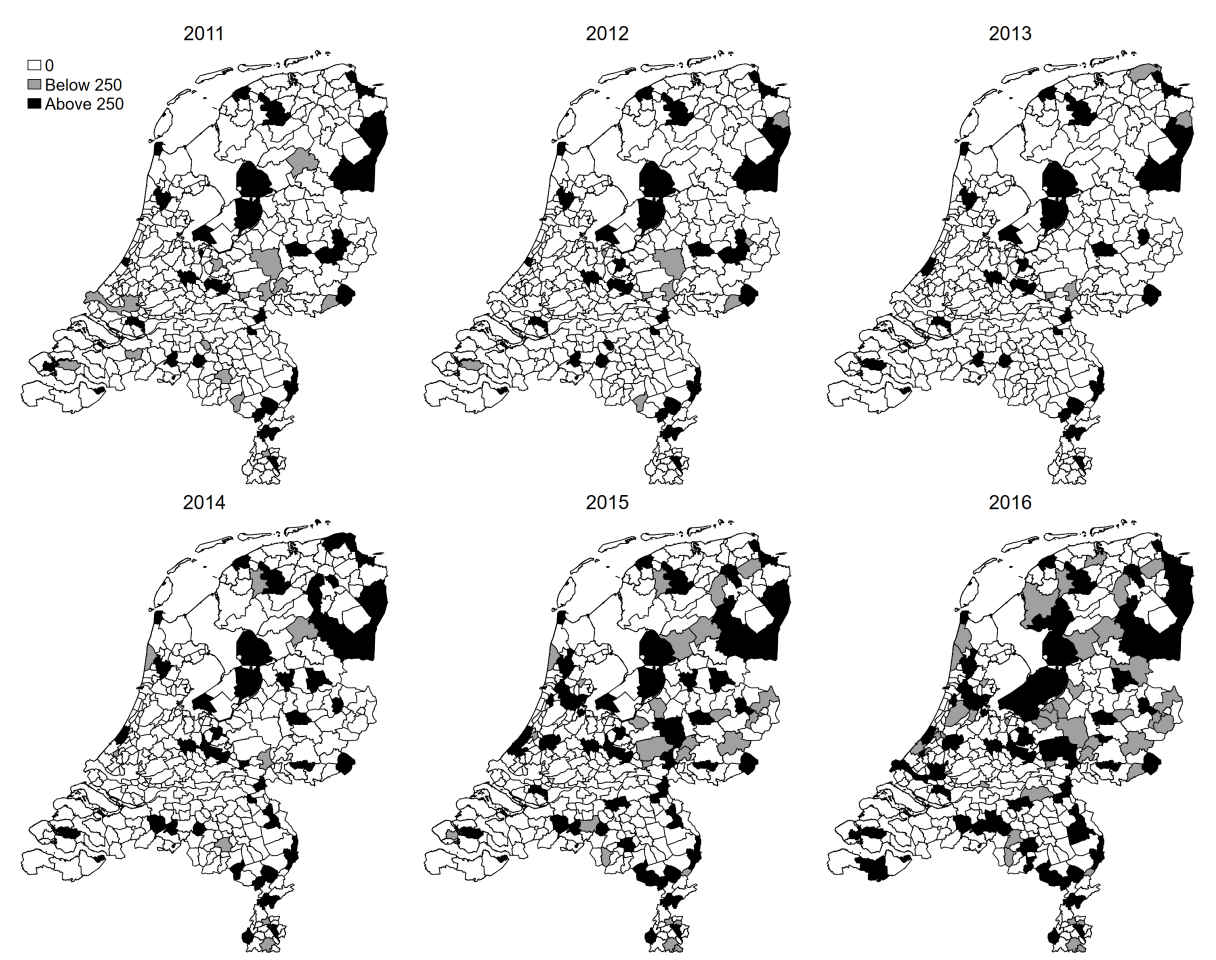

Notes: The maps show the distribution of refugees across municipalities in the Netherlands in years 2011 to 2016.

include cases in our analysis after which refugee centers closed down. ${ }^{11}$ Also for identification purposes, we focus on panelists who did not move to another postcode in the period of study. ${ }^{12}$ Postcodes cover on average a geographical area of about $2.3 \mathrm{~km}^{2}$ (about 0.89 squared miles) with roughly 7000 residents.

Our main estimation sample counts $21^{\prime} 878$ data points covering $5^{\prime} 654$ individual panelists, of which 49 percent are observed every year over the entire period from 2011 to $2016 .{ }^{13}$ About 24 percent of the panelists are observed twice, and 15 percent and 13 percent are observed respectively three and four times. The panelists live in 1'875 different neighborhoods, spread over 379 municipalities. Only 4.4 percent of the municipalities in the Netherlands are not repre-

\footnotetext{
${ }^{11}$ To be precise, we require that the refugee center did not close down more than six months before the time of measurement. Notice that the qualitative results are robust to including data points related to centers that have closed down. Notice also that the number of data points is too low to separately identify the effect of closure of centers on attitudes.

${ }^{12}$ For example, Tabellini (2019) shows that locals may move away due to the inflow of ethnic minorities. However, in our sample, the presence of refugees has no effect on individuals' decision to move (see Section B in the Appendix). Also, our results are robust to including panelists who have moved in the period of study (see Section 5.3).

${ }^{13}$ There are no observations for 2014 as the LISS survey was not carried out in that year.
} 
sented. ${ }^{14}$ Table 1 provides an overview of a number of statistics for neighborhoods in the whole of the Netherlands and for those included in our main estimation sample, split by whether they host refugees or not. The statistics are based on years before the large inflow of refugees took place. As can be seen in the table, neighborhoods in the main estimation sample generally have a larger population than the average neighborhood in the Netherlands. Also, neighborhoods that host refugees have more inhabitants than neighborhoods that do not host refugees, which is in line with the policy of COA of balancing the share of refugees with respect to the local population. Moreover, in comparison to neighborhoods not hosting refugees, neighborhoods hosting refugees have a significantly lower share of inhabitants below age 20, a higher share of inhabitants between 20 and 30 years old, and a higher share of inhabitants above 70 . Also, they live less frequently in areas with a low population density, are six percentage points less likely to own a house, and the distance to the closest doctor and supermarket is significantly lower. Given that there are a number of (arguably minor) differences between neighborhoods hosting and not hosting refugees, in our empirical strategy we control for any potential time-invariant difference by including individual-level fixed effects and for changing population size of the neighborhoods. Importantly, these statistics show that refugees are not located in remote areas.

\section{Empirical strategy}

Our empirical strategy can be summarized as follows: (a) use individual-level fixed-effects regressions to estimate the effect of exposure to ethnic minorities on attitudes towards them and (b) show that it is plausible to interpret the estimated effect as a causal effect. In what follows we describe the dependent and independent variables in detail, and provide details about our estimation method and identifying assumptions. The last subsection introduces a municipal-level analysis and discusses how this helps interpreting neighborhood-level effects.

\footnotetext{
${ }^{14}$ In 2016, the Netherlands had 391 municipalities. Because there is a tendency to merge smaller municipalities, the number of municipalities is declining every year. We treated the municipalities in 2016 as benchmark and aggregated the statistics of former, merging municipalities as far as possible. Three municipalities whose postcodes were split up and allocated to other municipalities were dropped from the sample.
} 
Table 1: Neighborhoods in the Netherlands and in our sample

\begin{tabular}{|c|c|c|c|}
\hline & \multirow{2}{*}{$\begin{array}{l}\text { The Netherlands } \\
\text { Mean (s.d.) }\end{array}$} & \multicolumn{2}{|c|}{ Main estimation sample } \\
\hline & & $\begin{array}{l}\text { Not hosting refugees } \\
\text { Mean (s.d.) }\end{array}$ & $\begin{array}{l}\text { Hosting refugees } \\
\text { Mean (s.d.) }\end{array}$ \\
\hline Number of inhabitants & $8229.8(4357.0)$ & $9262.5(4075.8)$ & $10052.2(4028.6)$ \\
\hline Share of non-Western immigrants & $0.116(0.135)$ & $0.119(0.126)$ & $0.141(0.165)$ \\
\hline \multicolumn{4}{|l|}{ Age distribution } \\
\hline 0-10 years & $0.113(0.029)$ & $0.114(0.029)$ & $0.101(0.021)^{* * *}$ \\
\hline $10-20$ years & $0.120(0.025)$ & $0.119(0.024)$ & $0.110(0.025)^{* * *}$ \\
\hline 20-30 years & $0.123(0.057)$ & $0.124(0.056)$ & $0.144(0.073)^{* *}$ \\
\hline $30-40$ years & $0.125(0.033)$ & $0.127(0.033)$ & $0.122(0.030)$ \\
\hline $40-50$ years & $0.154(0.023)$ & $0.154(0.023)$ & $0.145(0.023)^{* * *}$ \\
\hline $50-60$ years & $0.139(0.026)$ & $0.137(0.024)$ & $0.134(0.024)$ \\
\hline $60-70$ years & $0.116(0.030)$ & $0.115(0.030)$ & $0.118(0.028)$ \\
\hline $70-80$ years & $0.069(0.026)$ & $0.069(0.026)$ & $0.076(0.023)^{* *}$ \\
\hline $80-90$ years & $0.035(0.019)$ & $0.035(0.019)$ & $0.042(0.018)^{* * *}$ \\
\hline Above 90 years & $0.006(0.005)$ & $0.006(0.005)$ & $0.008(0.005)^{* * *}$ \\
\hline$N_{1}$ & 4033 & 1678 & 63 \\
\hline \multicolumn{4}{|l|}{ Population density } \\
\hline Very low & $0.025(0.155)$ & $0.007(0.084)$ & $0.000(0.000)^{* * *}$ \\
\hline Low & $0.072(0.258)$ & $0.041(0.199)$ & $0.009(0.098)^{* *}$ \\
\hline Middle & $0.172(0.378)$ & $0.148(0.355)$ & $0.133(0.342)$ \\
\hline High & $0.322(0.467)$ & $0.356(0.479)$ & $0.349(0.480)$ \\
\hline Very high & $0.409(0.492)$ & $0.448(0.497)$ & $0.509(0.504)$ \\
\hline Income by inhabitant (in 1000 Euro) & $22.4(4.0)$ & $22.5(3.7)$ & $22.6(4.7)$ \\
\hline Share of inhabitants on benefit & $0.069(0.021)$ & $0.069(0.020)$ & $0.071(0.018)$ \\
\hline House value (in 1000 Euro) & $229.4(76.3)$ & $226.3(67.4)$ & $222.2(79.5)$ \\
\hline Share of house owners & $0.572(0.167)$ & $0.566(0.161)$ & $0.508(0.159)^{* * *}$ \\
\hline Distance to doctor (in km) & $0.95(0.74)$ & $0.85(0.48)$ & $0.78(0.32)^{*}$ \\
\hline Distance to supermarket (in km) & $0.88(0.69)$ & $0.79(0.44)$ & $0.68(0.27)^{* * *}$ \\
\hline Distance to school (in km) & $0.65(0.32)$ & $0.62(0.23)$ & $0.62(0.17)$ \\
\hline$N_{2}$ & \pm 3700 & \pm 1650 & 63 \\
\hline
\end{tabular}

Notes: Reported statistics are weighted averages across neighborhoods with number of inhabitants by neighborhood as weights. Standard deviations are in parentheses. The period on which the data are based are pre-exposure years 2011-2013 for number of inhabitants, share of ethnic minorities and age distribution (standard deviations refer to between-neighborhood variation; number of neighborhoods indicated by $N_{1}$ ), and 2013 for all other variables (number of neighborhoods indicated by $N_{2}$ ). The share of non-Western immigrants refers to the share of first- or second-generation immigrants with a non-Western immigration background in the population. Data on population density refer to quintiles. The share of inhabitants on benefit refers to the share of inhabitants on social security because they are unemployed or unfit for the labor market (does not include retired). Differences between neighborhoods Hosting refugees and Not hosting refugees are statistically significant if marked with an asterisk (*significant at $10 \% ;{ }^{* *}$ significant at $5 \% ;{ }^{* * *}$ significant at $1 \%$ ).

\subsection{Dependent variable}

We construct the dependent variable based on LISS survey items related to attitudes to immigration and ethnic diversity in society, measured on five-point Likert scales. In the period we study the survey has been run each year in December with the exception of 2014, when it was not administered. The survey contains eight items. Out of these, the following six items reflect 
normative opinions: ${ }^{15}$

1. It is good if society consists of people from different cultures.

2. It should be made easier to obtain asylum in the Netherlands.

3. Legally residing foreigners should be entitled to the same social security as Dutch citizens.

4. There are too many people of foreign origin or descent in the Netherlands.

5. It does not help a neighborhood if many people of foreign origin or descent move in.

6. Some sectors of the economy can only continue to function because people of foreign origin or descent work there.

Averaged into one indicator, the answers to these statements form our dependent variable, which we refer to as Attitude to ethnic diversity. An average score of 1 corresponds to the most negative attitude to ethnic diversity and a score of 5 to the most positive. ${ }^{16}$ The statements are significantly correlated with each other with correlation coefficients ranging between 0.210 and 0.554. The average of the index in our main estimation sample is equal to 2.894 (within-panelist standard deviation of 0.260 ), and does not differ much from that of the full LISS sample across the period of study (average of 2.906, within-panelist standard deviation of 0.259). Table A.1 in the Appendix shows averages and standard deviations by year for our main estimation sample and for the full LISS sample.

\subsection{Independent variables}

The locations of the refugee centers determine how close refugees geographically are to the LISS panelists, and thus provide proxies for the extent to which panelists are exposed to refugees. To match the exposure variables with the yearly attitudes of panelists, we collapse monthly information on refugee centers into yearly variables. We run three sets of regressions, each with different exposure variables.

Exposure as a binary variable In a first set of regressions, we use a variable labeled Exposed $_{n t}$. The variable equals one for neighborhood $n$ and year $t$ if at least one refugee center was open in $n$ for at least one month in $t$.

\footnotetext{
${ }^{15}$ We do not include the following two items because these reflect positive statements: (a) It is difficult for a foreigner to be accepted in the Netherlands while retaining his/her own culture; and (b) People of foreign origin or descent are not accepted in the Netherlands.

${ }^{16}$ Negatively framed questions are coded in reverse before being aggregated.
} 
Duration of exposure Refugee centers open (and close) in different months during the year and remain open for different lengths of time. This generates variation in the duration of exposure at the time when attitudes are elicited. Moreover, duration may vary within exposed panelists; right after refugees have arrived, panelists are exposed for a short time and the year thereafter they are by definition exposed for a longer time, unless the refugee center closed down. We split up the duration of exposure into two categories depending on whether at the time of the attitudes measurement the center was open for less or more than six months. Six months is about equal to the median number of months that refugees stay in a center in our sample. ${ }^{17}$

Number of refugees There is also variation in terms of numbers of refugees in the centers. In order to calculate a yearly number from the monthly data, we take the number of refugees present in the centers located in postcode $n$ averaged over the months in which the centers are open in year $t$. We then construct a categorical variable using the median of this number, which is about 250 , as a threshold. ${ }^{18}$

In addition to the exposure variables, we include year dummies and time-varying individual, neighborhood- and municipal-level covariates as controls. The individual-level covariates include age, age squared, the number of children in the household, and categorical variables referring to highest level of education, and civil status. We find it plausible to assume that these variables are not influenced by the presence of refugees in the neighborhood. Neighborhoodlevel and municipal covariates include the number of registered inhabitants in the neighborhood and the municipality, respectively.

Table 2 gives an overview of the means and standard deviations of the dependent and independent variables for the full LISS sample and the main estimation sample in the period of study (first two columns). Within the estimation sample, we separate between individuals who live in a neighborhood without refugee centers and individuals who have experienced the opening of a center (last two columns). As can be seen from comparing the first two columns, the composition of our main estimation sample is very similar to that of the LISS sample in terms of gender, age, education, etc., which suggests that panelists responding to the survey

\footnotetext{
${ }^{17}$ The variation in the data is not large enough to justify using duration as a continuous variable.

${ }^{18}$ We use a categorical variable because it is a priori unclear how the functional form of the relation between number of refugees and attitudes should look like. Results are similar if using number of refugees.
} 
Table 2: Descriptive statistics dependent and independent variables

\begin{tabular}{lcccc}
\hline & $\begin{array}{c}\text { LISS panel } \\
\text { Mean (s.d.) }\end{array}$ & $\begin{array}{l}\text { Main sample } \\
\text { Mean (s.d.) }\end{array}$ & $\begin{array}{c}\text { Non-exposed } \\
\text { Mean (s.d.) }\end{array}$ & $\begin{array}{c}\text { Exposed } \\
\text { Mean (s.d.) }\end{array}$ \\
\hline Attitude & $2.934(0.628)$ & $2.909(0.624)$ & $2.909(0.627)$ & $2.910(0.544)$ \\
Male & $0.459(0.498)$ & $0.462(0.499)$ & $0.463(0.499)$ & $0.439(0.497)$ \\
Age & $47.4(18.1)$ & $51.7(16.8)$ & $51.7(16.8)$ & $51.3(17.0)$ \\
Number of children & $0.83(1.12)$ & $0.804(1.09)$ & $0.80(1.08)$ & $0.79(1.23)$ \\
Education & & & & \\
$\quad$ Primary school & $0.092(0.278)$ & $0.087(0.272)$ & $0.087(0.271)$ & $0.099(0.292)$ \\
$\quad$ Junior high school & $0.222(0.410)$ & $0.246(0.424)$ & $0.247(0.425)$ & $0.223(0.412)$ \\
$\quad$ Senior high school & $0.125(0.320)$ & $0.108(0.300)$ & $0.107(0.299)$ & $0.128(0.332)$ \\
$\quad$ Junior college & $0.234(0.419)$ & $0.238(0.420)$ & $0.238(0.420)$ & $0.245(0.427)$ \\
$\quad$ College & $0.224(0.412)$ & $0.232(0.417)$ & $0.234(0.418)$ & $0.185(0.388)^{*}$ \\
$\quad$ University & $0.102(0.299)$ & $0.089(0.281)$ & $0.087(0.278)$ & $0.121(0.324)$ \\
Civil status & & & & \\
$\quad$ Married & $0.500(0.493)$ & $0.580(0.486)$ & $0.581(0.486)$ & $0.558(0.493)$ \\
$\quad$ Divorced & $0.091(0.283)$ & $0.093(0.286)$ & $0.095(0.287)$ & $0.066(0.248)^{*}$ \\
$\quad$ Widow(er) & $0.052(0.218)$ & $0.060(0.233)$ & $0.061(0.234)$ & $0.051(0.220)$ \\
$\quad$ Never married & $0.352(0.475)$ & $0.262(0.436)$ & $0.259(0.435)$ & $0.324(0.466)$ \\
Share of movers & $0.210(0.408)$ & $0.222(0.416)$ & $0.222(0.416)$ & $0.235(0.425)$ \\
$N \quad \pm 8750$ & 5651 & 5414 & 237 \\
\hline
\end{tabular}

Notes: The statistics are calculated from individual-level data points in the period 2011-2016. For each individual we first calculated an average for the period 2011-2016 and then calculated the mean and the standard deviation of the individual-level averages. The share of minorities refers to the share of non-Western immigrants in the population. Urbanization categories refer to the number of addresses per squared kilometer (extremely urban is 2500 or more; very is between 1500 and 2500; moderately is between 1000 and 1500; slightly is between 500 and 1000; not is below 500). Differences between Exposed and Non-exposed are statistically significant if marked with an asterisk ( ${ }^{*}$ significant at $10 \%$; ${ }^{* *}$ significant at $5 \%$; ${ }^{* * *}$ significant at $\left.1 \%\right)$.

questions on ethnic diversity and immigrants are not a selected group. If we compare individuals exposed to refugees to those non-exposed, we find that the two subgroups do not differ much in terms of most of the background characteristics. Some differences can be detected in the percentage that has a university degree and a college degree, and in the divorce rate.

\subsection{Municipal exposure}

We also study the effect of the presence of refugees on attitudes of panelists who live in the same municipality where a center is located. Given that the municipality is a wider geographical area than the neighborhood, equivalent to the size of about 12 neighborhoods, the municipal presence of refugees generates the same or weaker exposure. It is therefore relevant to compare the effect of refugees in the neighborhood to that of refugees in the municipality. If municipal effects turn out to be different from neighborhood effects, then we can be confident that the municipal effects cannot be attributed to more (physical) exposure. Instead, they must then come from other forms of awareness or from sharing a common administrative jurisdiction with the refugees. We use the above-defined set of three dependent variables (exposure dummy, dura- 
tion of exposure and number of refugees) to estimate two additional specifications. In the first of these, we replace neighborhoods as geographical areas by municipalities, which allows to study the effect of the presence of refugees who live in the same municipality as the panelists. In a second specification we study the effect of the presence of refugees who live in the same municipality as the panelists but excluding those panelists who live in the same neighborhood as the refugees. This provides a cleaner sample if effects at neighborhood level and municipal level are different.

\subsection{Estimation and identification strategy}

Our estimation strategy is built around the panel structure of the data set. We include individual fixed effects in our regressions, which controls for stable unobservable differences between exposed and non-exposed individuals that play a role in shaping attitudes. Regression results can then be interpreted as relating changes in attitudes to changes in exposure. Equation 1 presents our estimation equation, where subscript int refers to individual $i$ in neighborhood $n$ in year $t$.

$$
\text { Attitude }_{\text {int }}=\beta_{0 i}+\beta_{1} \text { Exposure }_{n t}+\beta_{2} X_{\text {int }}+\tau_{t}+e_{\text {int }}
$$

$\beta_{0 i}$ refers to the individual fixed effects. Exposure Ext denotes a variable that is either equal to a treatment dummy or is based on the length of exposure or number of refugees present in neighborhood $n$ in year $t$. $\tau_{t}$ refers to year fixed effects. $X_{i n t}$ is a vector of control variables that includes time-varying individual, neighborhood and municipal characteristics. In all regressions we use heteroskedasticity-robust standard errors that account for clustering at the level of treatment assignment (i.e. neighborhood or municipal).

The largest concern for endogeneity of exposure is that individuals who live in places that host a refugee center generally have a more positive attitude, or that they have some unobserved characteristics that would bias the effect of exposure if omitted from the analysis. This concern is removed by including individual fixed effects. What could be a concern, though, is that attitudes of individuals who live in neighborhoods not hosting refugees evolve differently than attitudes of individuals who live in neighborhoods hosting refugees for other reasons than the presence of refugees. Indeed, our main identification assumption is that, conditional on the fixed effects and the covariates, the dependent variable would have followed a similar

pattern for treated individuals as for the control group if treated individuals would not have been treated. To show that this is a plausible assumption, we conduct the following analyses 
and report these in Section :

- We test whether in pre-exposure years attitudes of individuals in neighborhoods with a refugee center follow a different pattern than those of individuals in the control group (Section 5.1). We include results from an analysis in which the pre-exposure period is extended beyond the period used in our main estimations to include years 2008 to $2010 .{ }^{19}$

- We study the robustness of the neighborhood-level effects to redefining the control group in two ways (Section 5.2). First, instead of including all neighborhoods that do not host refugees in the control group, we only include neighborhoods not hosting refugees in municipalities hosting refugees. This allows us to get rid of unobserved time-varying differences between municipalities hosting and not hosting refugees. ${ }^{20}$ Second, in order to exclude that effects in the neighborhood are driven by exposure effects at the municipal level, we exclude neighborhoods not hosting refugees in municipalities hosting refugees from the control group.

- We perform several other robustness checks (Section 5.3).

- We run placebo tests by conducting randomization exercises in which we randomly reassign the values of the exposure variables (Section 5.4).

- We run our regressions using a dependent variable that builds upon opinions about societal norms that we expect to be unrelated to the presence of refugees (Section 5.5).

\section{Main results}

We report general results in Section 4.1 and focus on heterogeneous effects in Section 4.2.

\subsection{Effect of exposure on attitudes}

Table 3 shows the results of regressions in which the exposure variable is binary and in which all available control variables are included. The main level of analysis, shown in column (1), refers to the effect of exposure within the neighborhood. Columns (2) and (3) refer to the effect of the presence of refugees within the municipality, respectively with and without the own

\footnotetext{
${ }^{19}$ The data from 2008 to 2010 do not contain information about the number of refugees hosted and the length of opening of the centers, which made it impossible to use the data in the main analysis.

${ }^{20}$ Recall that the decision to host refugees is made at the municipal level.
} 
Table 3: Effect of exposure on attitudes

\begin{tabular}{lcccccc}
\hline & \multicolumn{2}{c}{$(1)$} & \multicolumn{2}{c}{$(2)$} & \multicolumn{2}{c}{$(3)$} \\
Neighborhood & Municipal & \multicolumn{2}{c}{ Municipal w/o neighb. } \\
$\begin{array}{l}\text { Dep. var.: } \\
\text { Attitude }\end{array}$ & Est. (S.E.) & $p$-value & Est. (S.E.) & $p$-value & Est. (S.E.) & $p$-value \\
\hline Exposed & $0.032(0.033)$ & 0.338 & $-0.018(0.013)$ & 0.186 & $-0.027(0.014)$ & 0.050 \\
Adj. $R^{2}$ & 0.009 & 0.008 & 0.008 & \\
\# Panelists & 5651 & 4968 & 4948 & \\
\# Data points & 21872 & 19174 & 18944 & \\
\hline
\end{tabular}

Notes: Results are reported of linear regressions of Attitude on a binary exposure variable. The variable indicates whether refugees are present within the indicated geographical area. All specifications include individual and year fixed effects, and the standard set of individual-, neighborhood-, and municipality-level control variables (listed in Section 3.2).

neighborhood. ${ }^{21}$ Given that the regressions include individual fixed effects, estimated coefficients can be taken to express within-individual changes in attitudes on a five-points scale, and effect sizes are calculated using within-individual standard deviations. As can be seen in Table 3, the effect of the presence of refugees in a panelist's neighborhood is positive but weak $(p=0.338)$. The effect of their municipal presence is negative and weak $(p=0.186)$. The results under (3) show that the effect of the presence of refugees who live in the same municipality as panelists but not in the same neighborhood is negative and marginally significant. The effect size corresponds to 10 percent of a standard deviation $(p=0.050)$. As can be seen in tables A.2, A.3 and A.4, the estimated coefficients are largely stable to the inclusion of different sets of control variables.

We now focus on the separate effects of duration of exposure and numbers of refugees. Table 4 separates the general treatment effect into exposure that has lasted shorter and exposure that has lasted longer than six months. Results in (1) show that, on the one hand, there is a positive and statistically significant effect of the presence of refugees in the neighborhood if exposure lasts longer than six months. The estimated coefficient is 0.088 ( $p=0.007)$, which accounts for 34 percent of a standard deviation. On the other hand, exposure lasting less than 6 months has a weak negative effect of $-0.016(p=0.752)$. Another interesting observation shown in (2) and, in particular, (3) is that the presence of refugees in the municipality has a negative effect in the short run that tends to fade in the long run. To illustrate, the short-run effect of

\footnotetext{
${ }^{21}$ The samples for the municipal regressions are smaller than the main estimation sample because they exclude panelists who live in a municipality that hosts refugees during the entire period of study. Those panelists are always treated at the municipal level. Moreover, in column (3) post-exposure observations of panelists who live in the same neighborhood as a refugee center are excluded.
} 
Table 4: Effect of duration of exposure on attitudes

\begin{tabular}{lcccccc}
\hline & \multicolumn{2}{c}{$(1)$} & \multicolumn{2}{c}{$(2)$} & \multicolumn{2}{c}{$(3)$} \\
Neighborhood & Municipal & \multicolumn{2}{c}{ Municipal w/o neighb. } \\
$\begin{array}{l}\text { Dep. var.: } \\
\text { Attitude }\end{array}$ & Est. (S.E.) & $p$-value & Est. (S.E.) & $p$-value & Est. (S.E.) & $p$-value \\
\hline Exposed short & $-0.016(0.050)$ & 0.752 & $-0.029(0.017)$ & 0.095 & $-0.036(0.017)$ & 0.036 \\
Exposed Long & $0.088(0.033)$ & 0.007 & $-0.005(0.015)$ & 0.717 & $-0.017(0.016)$ & 0.279 \\
Wald test & $-0.104(0.051)$ & 0.044 & $-0.024(0.018)$ & 0.185 & $-0.019(0.018)$ & 0.310 \\
Adj. $R^{2}$ & 0.010 & & 0.008 & 0.008 & \\
\# Panelists & 5651 & 4968 & 4948 & \\
\# Data points & 21872 & 19174 & & 18944 &
\end{tabular}

Notes: Results are reported of linear regressions of Attitude on categories of duration of exposure. The baseline category is no exposure. The two exposure categories are Exposed short (six months or less) and Exposed long (more than six months). Also included are results of Wald tests that test whether the two estimated effects are statistically different. All specifications include individual and year fixed effects, and the standard set of individual-, neighborhood-, and municipality-level control variables (listed in Section 3.2).

Table 5: Effect of number of refugees on attitudes

\begin{tabular}{lcccccc}
\hline & \multicolumn{2}{c}{$\begin{array}{c}(1) \\
\text { Neighborhood }\end{array}$} & $\begin{array}{c}(2) \\
\text { Municipal }\end{array}$ & \multicolumn{2}{c}{$\begin{array}{c}\text { Municipal w/o neighb. } \\
\text { Dep. var.: }\end{array}$} & \multicolumn{2}{c}{ (3) } \\
Attitude & Est. (S.E.) & $p$-value & Est. (S.E.) & $p$-value & Est. (S.E.) & $p$-value \\
\hline Below 250 & $0.036(0.036)$ & 0.314 & $-0.027(0.019)$ & 0.157 & $-0.036(0.019)$ & 0.065 \\
Above 250 & $0.026(0.063)$ & 0.686 & $-0.010(0.015)$ & 0.507 & $-0.019(0.016)$ & 0.217 \\
Wald test & $0.010(0.075)$ & 0.889 & $-0.017(0.021)$ & 0.423 & $-0.017(0.022)$ & 0.443 \\
Adj. $R^{2}$ & 0.009 & 0.008 & & 0.008 & \\
\# Panelists & 5651 & 4968 & 4948 & \\
\# Data points & 21872 & 19174 & \multicolumn{2}{c}{18944} &
\end{tabular}

Notes: Results are reported of linear regressions of Attitude on categories of numbers of refugees. The baseline category is zero. The two number categories are less than 250 refugees and more than 250 refugees. Also included are results of Wald tests that test whether the two effects are significantly different. All specifications include individual and year fixed effects, and the standard set of individual-, neighborhood-, and municipality-level control variables (listed in Section 3.2).

refugees present in the municipality but outside of the neighborhood corresponds to 14 percent of a standard deviation. Finally, the effect of long exposure is overall more positive than that of short exposure, and this difference between long and short is statistically significant for the neighborhood. We consider results reported in Table 4 as our main results. Tables A.5, A.6 and A.7 in the Appendix show that the estimated effects are robust to the inclusion of different sets of control variables.

Finally, Table 5 displays treatment effects depending on whether less or more than 250 refugees are hosted (see also tables A.8, A.9, and A.10 in the Appendix). Estimation results indicate that the direction and effect sizes reported in Table 3 are largely uninfluenced by the number of people residing in the centers. 


\subsection{Heterogeneous effects}

The heterogeneity in our sample allows testing whether the effects of exposure are different for different socio-economic groups. We focus on gender, age, the presence of children in the household, and the degree of urbanization. For the sake of brevity, we focus on heterogeneity in effects of short and long exposure to refugees within the neighborhood (reported in Table 6). We do not detect meaningful heterogeneous effects if exposure is defined as a binary variable or if taking into account the number of refugees, nor for exposure within the municipality. ${ }^{22}$

Our first result relates to gender. We find that exposure to refugees in the neighborhood has positive and significant effects on attitudes for female panelists, but less so for male panelists. In the female sample, the effect of exposure is positive in all specifications, and strongest when exposure is long-lasting: attitudes improve by 0.12 points $(p=0.007)$ when a center is located in the same postcode of a female panelist for at least 6 months. Regressions conducted with male panelists show, instead, that exposure does not change attitudes in a meaningful way. When exposure is long-lasting, we observe that attitudes improve by 0.057 points but the effect is statistically not significant. ${ }^{23}$

Next, we test whether effects of exposure are different among panelists whose age in the period of study is below age 55 (i.e. the median age) than among panelists who are above age 55 in the entire period of study. As can be seen in Table 6, the positive effect of long exposure is particularly strong among panelists below age 55. For panelists above 55, long exposure also has a positive effect but the effect is statistically not significant.

We also test whether the effects of exposure are different for panelists who live together with children in their household and panelists who live without. This is relevant since refugee children go to school in the area where they live. We find that for panelists living with children the effect of exposure to refugees in the neighborhood is positive in all specifications and particularly substantial, namely equal to 0.157 points, when exposure is long-lasting ( $p=0.007$ ). For panelists who do not live with children, exposure has basically no effect on attitudes.

Finally, we slice up the data according to the degree of urbanization. The category 'most urbanized' includes panelists who live in areas with a population density higher than 1500

\footnotetext{
${ }^{22}$ Results related to the duration of exposure at the municipal level are in Table A.13 in the Appendix and other results are available upon request.

${ }^{23}$ These results are consistent with Albrecht and Smerdon (2019) who find that only women behave more prosocially towards out-group due to increased contact with out-group.
} 
Table 6: Heterogeneous effects of exposure at the neighborhood level

\begin{tabular}{|c|c|c|c|c|}
\hline Dep. var.: Attitude & Est. (S.E.) & $p$-value & Est. (S.E.) & $p$-value \\
\hline & \multicolumn{2}{|c|}{ Female } & \multicolumn{2}{|l|}{ Male } \\
\hline Exposed short & $0.033(0.058)$ & 0.568 & $-0.079(0.063)$ & 0.207 \\
\hline Exposed long & $0.123(0.046)$ & 0.007 & $0.057(0.040)$ & 0.156 \\
\hline Adj. $R^{2}$ & 0.008 & & 0.014 & \\
\hline \# Panelists & 3043 & & 2608 & \\
\hline \multirow[t]{2}{*}{ \# Data points } & 11635 & & 10237 & \\
\hline & \multicolumn{2}{|c|}{ Age below 55} & \multicolumn{2}{|c|}{ Age above 55} \\
\hline Exposed short & $-0.049(0.068)$ & 0.471 & $0.036(0.053)$ & 0.500 \\
\hline Exposed long & $0.135(0.062)$ & 0.029 & $0.037(0.042)$ & 0.371 \\
\hline Adj. $R^{2}$ & 0.008 & & 0.016 & \\
\hline \# Panelists & 2787 & & 2864 & \\
\hline \multirow[t]{2}{*}{ \# Data points } & 9877 & & 11995 & \\
\hline & \multicolumn{2}{|c|}{ With children } & \multicolumn{2}{|c|}{ Without children } \\
\hline Exposed short & $0.022(0.107)$ & 0.838 & $-0.036(0.042)$ & 0.390 \\
\hline Exposed long & $0.157(0.059)$ & 0.007 & $0.046(0.041)$ & 0.264 \\
\hline Adj. $R^{2}$ & 0.006 & & 0.015 & \\
\hline \# Panelists & 2421 & & 3230 & \\
\hline \multirow[t]{2}{*}{ \# Data points } & 9227 & & 12645 & \\
\hline & \multicolumn{2}{|c|}{ Most urbanized } & \multicolumn{2}{|c|}{ Least urbanized } \\
\hline Exposed short & $-0.062(0.061)$ & 0.311 & $0.048(0.071)$ & 0.496 \\
\hline Exposed long & $0.075(0.037)$ & 0.042 & $0.114(0.056)$ & 0.056 \\
\hline Adj. $R^{2}$ & 0.012 & & 0.013 & \\
\hline \# Panelists & 2211 & & 3425 & \\
\hline \# Data points & 8340 & & 13479 & \\
\hline
\end{tabular}

Notes: Results are reported for different subgroups of linear regressions of Attitude on categories of duration of exposure. The baseline category is no exposure. The two exposure categories are Exposed short (six months or less) and Exposed long (more than six months). All specifications include individual and year fixed effects, and the standard set of individual-, neighborhood-, and municipality-level control variables.

addresses per squared kilometer, whereas in the 'least urbanized' areas the density is below this number. As shown in Table 6, for panelists living in relatively rural areas we obtain a stronger positive effect of long exposure than for panelists in the most urban areas. 


\section{Identification analyses}

\subsection{Pre-trend analysis}

As a first step of the pre-trend analysis we run regressions based on pre-exposure data points in which the dependent variable Attitude is regressed on year dummies and year dummies interacted with a dummy that indicates whether an individual is part of the relevant treatment group, controlling for individual fixed-effects and the usual time-varying individual, neighborhood and municipality covariates. Results allow us to test whether pre-exposure levels in Attitude differ between the relevant treatment group and the associated control group. We focus on two definitions of treatment groups, one that relates to exposure within the neighborhood and one that relates to exposure outside of the neighborhood, and report results in Table 7. In our first definition, the treatment group includes individuals who have experienced refugees in their neighborhood for more than six months. The associated control group includes individuals who have not been exposed or have been exposed for at most six months. ${ }^{24}$ As can be seen in the first column of Table 7, the interactions with the year dummies are statistically not significant. In the second definition, the treatment group consists of individuals who have been exposed for less than six months to refugees in their municipality but outside of their neighborhood. The associated control group now consists of individuals who have never been exposed. The second column of Table 7 reveals that neither in this case are the interactions with the year dummies statistically significant. These results provide a first piece of evidence on the plausibility of the parallel-trend assumption.

In a next step, we test whether there is a difference in the trend of the Attitude variable between treatment and control by regressing the variable on a linear time trend and a trend interacted with a treatment dummy. We focus on the same two treatment groups as defined above. As shown in Table 8, we cannot reject the null that trends do not differ, for neither of the two treatment definitions.

As a final step in our pre-trends analysis, we extend the pre-exposure period with three years (see tables A.11 and A.12 in the Appendix). Results confirm that there is no indication that trends differ between treatment and control.

\footnotetext{
${ }^{24}$ Removing the individuals who have been exposed for at most six months from the control group has little effect on the estimation results.
} 
Table 7: Results of pre-exposure regressions with year dummies

\begin{tabular}{lcccc}
\hline & \multicolumn{2}{c}{$\begin{array}{c}\text { Exposed long } \\
\text { Neighborhood }\end{array}$} & \multicolumn{2}{c}{ Exposed short } \\
Depicipal w/o neighb. & Est. (S.E.) & $p$-value & Est. (S.E.) & $p$-value \\
\hline 2012 & $0.005(0.007)$ & 0.442 & $0.008(0.008)$ & 0.332 \\
2013 & $0.006(0.009)$ & 0.495 & $0.004(0.010)$ & 0.680 \\
2015 & $-0.037(0.013)$ & 0.005 & $-0.020(0.014)$ & 0.153 \\
2016 & $-0.053(0.016)$ & 0.001 & $-0.042(0.017)$ & 0.014 \\
Treatment group $\times 2012$ & $-0.036(0.041)$ & 0.380 & $0.005(0.015)$ & 0.731 \\
Treatment group $\times 2013$ & $-0.030(0.049)$ & 0.537 & $0.015(0.017)$ & 0.364 \\
Treatment group $\times 2015$ & $0.011(0.076)$ & 0.878 & $-0.006(0.030)$ & 0.843 \\
\hline Adjusted $R^{2}$ & 0.010 & \multicolumn{3}{c}{0.007} \\
\# Panelists & 5646 & 4059 & \\
\# Data points & 21749 & \multicolumn{3}{c}{14650} \\
\hline
\end{tabular}

Notes: Results are reported of linear regressions of Attitude on year fixed effects and interactions between year fixed effects and a dummy referring to the relevant treatment group. Data points come from individuals in the control group or from pre-exposure periods of individuals in the treatment group. All specifications include individual fixed effects and the standard set of individual-, neighborhood-, and municipality-level control variables.

Table 8: Results of pre-exposure regressions with trend

\begin{tabular}{|c|c|c|c|c|}
\hline \multirow{2}{*}{$\begin{array}{l}\text { Dep. var.: } \\
\text { Attitude }\end{array}$} & \multicolumn{2}{|c|}{$\begin{array}{l}\text { Exposed long } \\
\text { Neighborhood }\end{array}$} & \multicolumn{2}{|c|}{$\begin{array}{c}\text { Exposed short } \\
\text { Municipal w/o neighb. }\end{array}$} \\
\hline & Est. (S.E.) & $p$-value & Est. (S.E.) & $p$-value \\
\hline$t$ & $0.010(0.011)$ & 0.323 & $0.002(0.008)$ & 0.779 \\
\hline Treatment group $\times t$ & $0.016(0.023)$ & 0.496 & $0.010(0.007)$ & 0.130 \\
\hline Adjusted $R^{2}$ & \multicolumn{2}{|c|}{0.008} & \multicolumn{2}{|c|}{0.006} \\
\hline \# Panelists & \multicolumn{2}{|c|}{5646} & \multicolumn{2}{|c|}{4059} \\
\hline \# Data points & \multicolumn{2}{|c|}{21749} & \multicolumn{2}{|c|}{14650} \\
\hline
\end{tabular}

Notes: Results are reported of linear regressions of Attitude on a linear time trend and interactions between the trend and a dummy referring to the relevant treatment group. Data points come from individuals in the control group or from pre-exposure periods of individuals in the treatment group. All specifications include individual fixed effects and the standard set of individual-, neighborhood-, and municipality-level control variables.

\subsection{Redefining the control group}

We study the robustness of our main neighborhood results to redefining the control group in two alternative ways. First, in order to make the treatment group more comparable to the control group in terms of neighborhood characteristics, we remove all non-treated municipalities from the control group. This way the control group only includes individuals who live in municipalities (but not necessarily neighborhoods) that host refugees. Results are shown in Table 9, under redefined control I. As can be seen, the effect of long exposure is equal to 0.096 and statistically significant at the $1 \%$ level. This give us additional confidence that the positive long-run effect we had established using our main estimation sample is not due to municipal differences unrelated to the presence of refugees between neighborhoods hosting and not 
Table 9: Effect of neighborhood exposure with alternative control groups

\begin{tabular}{lcccc}
\hline & \multicolumn{2}{c}{ Redefined control I } & \multicolumn{2}{c}{ Redefined control II } \\
$\begin{array}{l}\text { Dep. var.: } \\
\text { Attitude }\end{array}$ & Est. (S.E.) & $p$-value & Est. (S.E.) & $p$-value \\
\hline Exposed Short & $-0.007(0.050)$ & 0.893 & $-0.019(0.050)$ & 0.700 \\
Exposed Long & $0.096(0.033)$ & 0.004 & $0.082(0.033)$ & 0.013 \\
Adj. $R^{2}$ & 0.013 & 0.008 & \\
\# Panelists & 2895 & 5379 & \\
\# Data points & 11132 & 17780 & \\
\hline
\end{tabular}

Notes: Results are reported of linear regressions of Attitude on a binary exposure variable (specification 1) or on categories of length of exposure referring to shorter and longer than 6 months (specification 2). All specifications include individual and year fixed effects, and the standard set of individual-, neighborhood-, and municipality-level control variables.

hosting refugees.

Furthermore, in order to study whether neighborhood effects mostly come from differences between neighborhoods hosting and not hosting refugees in the same municipality, we now exclude neighborhoods not hosting refugees in municipalities hosting refugees from the control group. As shown under redefined control II in Table 9, our main result that long-lasting exposure has a positive and significant effect on attitudes is recovered also if non-treated neighborhoods in treated municipalities are removed from the control group. The fact that the effect size is of the same order of magnitude is reassuring because it suggests that the positive effect of long-lasting exposure is not just due to individuals reacting negatively to the presence of refugees in their municipality but outside of their neighborhood.

\subsection{Robustness checks}

In order to check the robustness of our results, we include a series of robustness checks, of which results are reported in Section D of the Appendix. In particular, we show that results are qualitatively similar if we (i) choose different thresholds for either duration of exposure or refugee numbers (Section D.1); (ii) remove extreme attitudes from the sample (Section D.2); (iii) exclude the biggest cities or the largest refugee centers (Section D.3 and D.4, respectively), (iv) define the attitudes variable using principal components (Section D.5), (v) drop individuals with a non-Western immigrant background from our sample of respondents (Section D.6, (vi) control for a time trend and interactions between the trend and municipality dummies or dummies referring to urbanization categories (Section D.7). Finally, we show that the results hold up if we include panelists who move to another neighborhood in the period of study (Section D.8). In this analysis, we assign panelists who move to their first observed postcode for 
the entire length that they are observed. This allows us to estimate an intention-to-treat effect, which offers a lower bound on the effect of actual exposure to ethnic minorities. Results show that albeit the effects are qualitatively similar, the estimated coefficients are smaller than in the main analysis.

\subsection{Placebo tests}

Another way to test for the validity of our results is to study the effects of placebo treatments. We do this by randomly reassigning the values of the exposure variables to the panelists in the estimation sample. Importantly, we respect the years in which we observe panel members to avoid confounding this placebo test with effects of a general time trend in the population. The test essentially pretends that panelists lived in a random neighborhood, drawn from our estimation sample. We repeat the process 5000 times, each time estimating the effects of this placebo treatment. This gives us a distribution of counterfactual treatment effects, which we compare with the estimated treatment effects reported in tables 3 to 5 . Figure 3 shows distributions of the counterfactual treatment effects and associated $p$-values related to (a) long exposure within the neighborhood and (b) short exposure within the municipality excluding the neighborhood. Results for other exposure definitions are included in Section C of the Appendix. For ease of comparison, the empirical estimates are depicted as red vertical lines. In both cases the mean of the counterfactual estimates is centered around zero, as it should be, and the empirical estimate is larger in magnitude than the majority of the counterfactual estimates. It is thus very unlikely that the main estimation results are observed by chance.

\subsection{Unrelated dependent variables}

In this section we study the effects of the presence of refugees on two variables that capture norms in society, and that we expected to be unaffected by the presence of refugees. The first variable relates to marriage norms and the second variable to norms related to parental care. Both variables are indexes constructed using five-points scale survey items administered to the panelists in our sample. The index related to marriage norms is based on:

1. Married people are generally happier than unmarried people.

2. People that want to have children should get married.

3. A single parent can raise a child just as well as two parents together.

4. It is perfectly fine for a couple to live together without marriage intentions.

5. For a couple that wants to get married, it is good to first start living together.

6. A divorce is generally the best solution if a married couple cannot solve their marital problems. 
Figure 3: Results of placebo tests

(a) Exposed long neighborhood
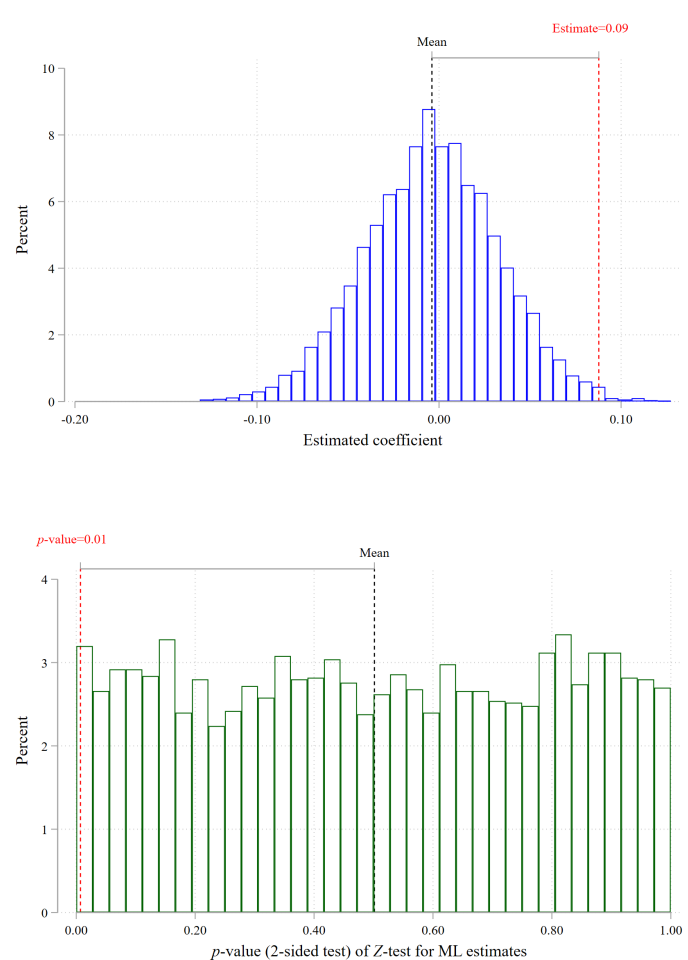

(b) Exposed short municipal w/o neighb.
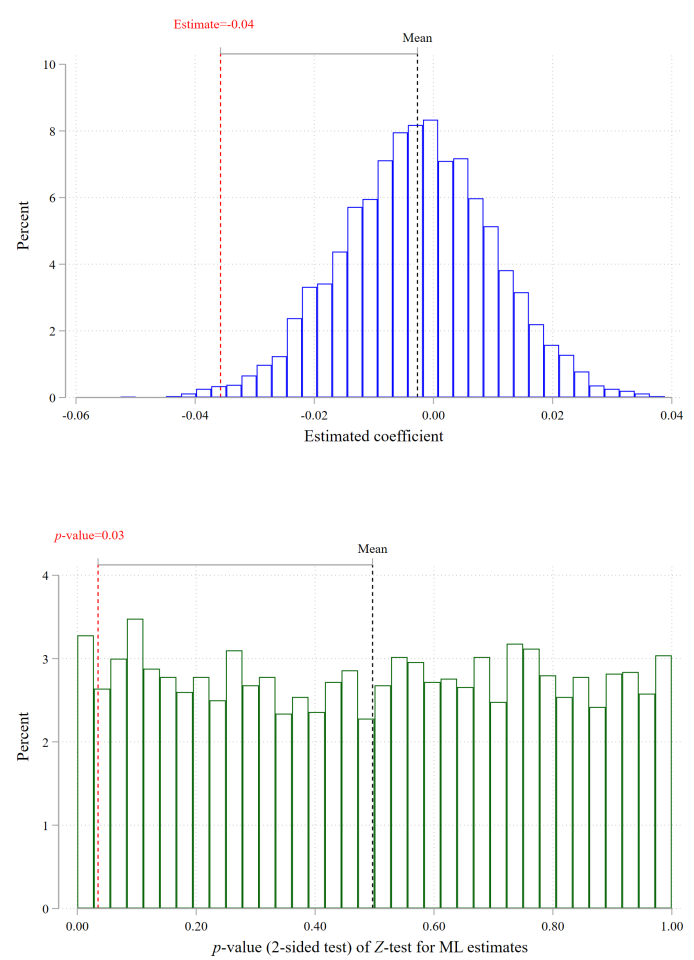

Notes: The figure shows the distribution of simulated counterfactual treatment estimates and $p$-values in the case the treatment relates to long exposure within the neighborhood (left-hand-side panels) or short exposure within the municipality excluding the neighborhood (right-hand-side panels).

The index related to norms of parental care contains the following items:

1. Children ought to care for their sick parents.

2. When parents reach old age, they should be able to live with their children.

3. Children that live close by ought to visit their parents at least once a week.

4. Children ought to take unpaid leave in order to care for their sick parents.

Table 10 reports the results of duration regressions using these alternative dependent variables. Neither short nor long exposure to refugees in the neighborhood or municipality have an effect on marriage and parental care norms. These results strengthen the idea that our main results are not due to societal norms generally evolving differently in locations in which a refugee center has opened than in other locations.

\section{Evidence from a lab-in-the-field experiment}

In this section we report the results of an analysis based on a behavioral measure of attitudes, namely discrimination against ethnic minorities elicited in an incentivized experiment. The 
Table 10: Effect of duration of exposure on unrelated norms

\begin{tabular}{|c|c|c|c|c|c|c|}
\hline & \multicolumn{2}{|c|}{$\begin{array}{c}(1) \\
\text { Neighborhood }\end{array}$} & \multicolumn{2}{|c|}{$\begin{array}{c}\text { (2) } \\
\text { Municipal }\end{array}$} & \multicolumn{2}{|c|}{$\begin{array}{c}(3) \\
\text { Municipal w/o neighb }\end{array}$} \\
\hline & Est. (S.E.) & $p$-value & Est. (S.E.) & $p$-value & Est. (S.E.) & $p$-value \\
\hline \multicolumn{7}{|c|}{ Dep. var.: Marriage norms } \\
\hline Exposed short & $-0.000(0.042)$ & 0.995 & $-0.007(0.011)$ & 0.502 & $-0.013(0.011)$ & 0.259 \\
\hline Exposed long & $-0.026(0.029)$ & 0.371 & $-0.006(0.012)$ & 0.638 & $-0.006(0.013)$ & 0.626 \\
\hline Wald test & $0.026(0.047)$ & 0.585 & $-0.001(0.012)$ & 0.906 & $-0.006(0.013)$ & 0.609 \\
\hline Adj. $R^{2}$ & \multicolumn{2}{|l|}{0.016} & \multicolumn{2}{|l|}{0.017} & \multicolumn{2}{|l|}{0.017} \\
\hline \multicolumn{7}{|c|}{ Dep. var.: Parental care norms } \\
\hline Exposed short & $-0.050(0.047)$ & 0.294 & $-0.016(0.018)$ & 0.368 & $-0.007(0.018)$ & 0.685 \\
\hline Exposed long & $0.047(0.053)$ & 0.375 & $-0.007(0.019)$ & 0.710 & $-0.005(0.018)$ & 0.772 \\
\hline Wald test & $-0.096(0.054)$ & 0.077 & $-0.009(0.020)$ & 0.664 & $-0.002(0.021)$ & 0.934 \\
\hline Adj. $R^{2}$ & \multicolumn{2}{|c|}{0.003} & \multicolumn{2}{|l|}{0.004} & \multicolumn{2}{|l|}{0.003} \\
\hline \# Panelists & \multirow{2}{*}{\multicolumn{2}{|c|}{$\begin{array}{c}5651 \\
21863\end{array}$}} & \multirow{2}{*}{\multicolumn{2}{|c|}{$\begin{array}{c}4968 \\
19167\end{array}$}} & \multirow{2}{*}{\multicolumn{2}{|c|}{$\begin{array}{c}4948 \\
18937\end{array}$}} \\
\hline \# Data points & & & & & & \\
\hline
\end{tabular}

Notes: Results are reported of linear regressions of Marriage norms and Parental care norms on categories of duration of exposure. The baseline category is no exposure. The two exposure categories are Exposed short (six months or less) and Exposed long (more than six months). Also included are results of Wald tests that test whether the two estimated effects are statistically different. All specifications include individual and year fixed effects, and the standard set of individual-, neighborhood-, and municipality-level control variables.

experiment was run on a subsample of LISS panelists. Of those, panelists with a native Dutch background participated in the role of trustee in binary trust games. The trustees were randomly matched to a trustor who also had a native Dutch background (Majority condition) or to a trustor with a non-Western immigration background (Minority condition). Lower reciprocation rates in Minority as compared to Majority are taken as evidence of discrimination.

Waves of the experiment were conducted in December 2014, February 2015, December 2015 and December 2016 (see Cettolin and Suetens, 2018, for a study using data from the first wave). Each time, a random sample was drawn of about 800 participants. In addition, in December 2016, all participants who made choices in the role of trustee in December 2014 and December 2015 were contacted to participate again. They remained in the same condition (either $\mathrm{Mi}$ nority or Majority). Because our objective here is to perform a panel data analysis, we focus on behavior of trustees who took part in two waves, either in 2014 and 2016 or in 2015 and 2016. Since the largest numbers of refugees arrived in 2015 and 2016, the experiment allows studying whether exposure to refugees affects the likelihood that native Dutch people discriminate against ethnic minorities in the role of trustee in the trust game. The key advantage of these data is that they describe choices that have material consequences for both the trustor and the trustee. The disadvantage is that the estimation sample is relatively small and selected, 
and that we observe behavior only twice for each individual. In what follows we describe the decision-making setting in the experiment, our empirical strategy and the results.

\subsection{Decision-making setting}

In each wave of the experiment native Dutch trustees played three binary trust games with the same trustor. In each game a trustor decided to trust or not. If he trusted, then the trustee decided whether to reciprocate trust or not. If he did not trust, the game ended. Trustees were asked for their reciprocation choice for the case that the matched trustor would trust. If the trustor decided not to trust, both trustor and matched trustee earned $€ 35$ in all three games. If the trustor decided to trust and the matched trustee did not reciprocate, the former earned $€ 20$ and the latter earned $€ 85$ in all three games. If the trustor decided to trust and the matched trustee reciprocated, then the payoffs were respectively $€ 40, € 60$, and $€ 80$ in the three games. The participants were informed that they were paid a fixed amount for participating and that, in addition, there was about a one-out-of-forty chance of being paid for their choices. ${ }^{25}$ Before choices were elicited, participants were communicated the first name of the trustor as well as the gender and the age range (which was fixed between 16 and 89 years old). The name served as a signal of ethnic background.

After merging the data from the experiment with the data on refugee centers, we obtain a sample of 938 trustees who participated in the 2014 and 2016 waves of the experiment, or in the 2015 and 2016 waves. Of these, 489 were in condition Majority and 449 in condition Minority. After excluding panelists who were always exposed to a center during the period of study or moved to a different postcode, we obtain a sample of 780 panelists in total for the regressions at the neighborhood level, and respectively 642 and 637 panelists for municipal and municipal w/o neighborhood regressions. Details on procedures are provided in Section E of the Appendix.

\footnotetext{
${ }^{25}$ In the instructions, it was explained to the participants that at the end of the research five trustor/trustee pairs would be randomly drawn for payment among the 200 pairs that were expected to participate. The fixed fee was $€ 1.5$ and was calibrated by CentERdata on the basis of an expected duration of 6 minutes. In terms of hourly earnings, trustees could expect to earn around $€ 30$ an hour.
} 


\subsection{Empirical strategy}

In order to identify the effect of exposure to refugees on trustees' choices, we employ a similar approach to that used in the attitude regressions. In particular, we estimate the effect of exposure to refugees in one's neighborhood using individual fixed-effects regressions. We include the same set of control variables as in the attitude regressions and show results from regressions on municipal exposure, both including and excluding the own neighborhood.

A different aspect of the experimental data is that trustees make choices in one of two conditions (Majority or Minority), and that the key measure of interest is thus the difference in choices between Majority and Minority. More precisely, the dependent variable in the regressions, referred to as Reciprocation, is the number of times trustees reciprocate in the three trust games (between 0 and 3). The main independent variables are the binary exposure variable (cf. Section 3.2), a binary variable indicating whether the trustee is in the Minority condition, and the interaction between both variables. To study how exposure to ethnic minorities influences the behavioral measure of discrimination, we focus on the interaction effect. A positive (negative) interaction effect implies that exposure increases (decreases) reciprocal behavior towards minority vis-á-vis majority.

In terms of sample selection it is important to point out that the experimental data set covers about 13 percent of the panelists included in the main (attitudes) estimation sample. To illustrate, if we use the experimental sample to estimate the effect of exposure on attitudes, we find that attitudes become 0.259 points more positive among panelists who are exposed to refugees in their neighborhood ( $p=0.117$ ), versus 0.032 points in the large sample (see Table A.14 in the Appendix). The effect size based on the experimental sample is clearly much higher and not representative for the large sample, which leads us to interpret any effect size estimated using the experimental sample with care. Moreover, given the small sample size, it is not feasible to focus on aspects related to intensity of exposure. We thus focus on the simplest treatment definition, where exposure is captured by the binary variable for exposure in the neighborhood, the municipality or the municipality excluding the neighborhood.

\subsection{Results}

Table 11 shows the regression results. We find a positive and statistically significant interaction between being exposed and being part of the Minority condition. Native Dutch who have a refugee center in their neighborhood are thus more inclined to reciprocate trust by individuals 
Table 11: Effect of exposure on reciprocation

\begin{tabular}{|c|c|c|c|c|c|c|}
\hline \multirow[b]{2}{*}{$\begin{array}{l}\text { Dep. var: } \\
\text { Reciprocation }\end{array}$} & \multicolumn{2}{|c|}{$\begin{array}{c}(1) \\
\text { Neighborhood }\end{array}$} & \multicolumn{2}{|c|}{$\begin{array}{c}(2) \\
\text { Municipal }\end{array}$} & \multicolumn{2}{|c|}{$\begin{array}{c}\text { (3) } \\
\text { Municipal w/o neighb. }\end{array}$} \\
\hline & Est. (S.E.) & $p$-value & Est. (S.E.) & $p$-value & Est. (S.E.) & $p$-value \\
\hline Exposed & $-0.182(0.081)$ & 0.025 & $-0.141(0.058)$ & 0.016 & $-0.155(0.067)$ & 0.023 \\
\hline Exposed $\times$ Minority & $0.306(0.151)$ & 0.043 & $0.134(0.074)$ & 0.071 & $0.122(0.082)$ & 0.139 \\
\hline $\begin{array}{l}\text { Adjusted } R^{2} \\
\text { \# Panelists } \\
\text { \# Data points }\end{array}$ & $\begin{array}{c}0.025 \\
780 \\
1560\end{array}$ & & $\begin{array}{c}0.029 \\
642 \\
1284\end{array}$ & & $\begin{array}{r}0.028 \\
637 \\
1249\end{array}$ & \\
\hline
\end{tabular}

Notes: Results are reported of linear regressions of Reciprocation on a binary exposure variable. The variable indicates whether refugees are present within the indicated geographical area. All specifications include individual and year fixed effects, and the standard set of individual-, neighborhood-, and municipality-level control variables.

from ethnic minorities vis-à-vis trust by other native Dutch than trustees who live in a neighborhood without refugees. If we focus on exposure within the municipality or the municipality without the own neighborhood, we still find a positive interaction effect, but the effect is statistically not significant or marginally significant.

As we explain above, the sizes of the estimated effects should be interpreted with care. However, it is noteworthy that results based on behavioral data are largely in line with those based on the survey-measured attitude data in this experimental sample. This provides additional support for the assumption that self-reported attitudes are a meaningful proxy of behavior towards ethnic minorities.

\section{Discussion}

Prejudices against ethnic minorities are widespread and can lead to segregated societies (e.g. Alesina and La Ferrara, 2005). It is thus important to understand which conditions fuel prejudices and how these can be reduced. In this paper we exploit variation in the presence of refugees across the Netherlands to study whether exposure to ethnic minorities has a causal effect on attitudes towards them. We find that individuals who experience an inflow of refugees in their neighborhood develop a more positive attitude to ethnic diversity than individuals who are not exposed, provided that the exposure lasts sufficiently long. We also find that attitudes towards ethnic diversity worsen if refugees are present in one's municipality but not in the neighborhood of residence. These results demonstrate the great importance of neighborhoods in shaping social outcomes, in line with effects on mental health (Kling, Liebman and Katz, 2007; Ludwig et al., 2013) and employment and education Chetty et al. (2018). Moreover, 
they highlight that the level of aggregation of the available data may have a key influence on the obtained results. ${ }^{26}$

The difference in estimated effects between the neighborhood and the municipality level, and the result that only long-lasting exposure has a large positive effect but not short-lasting exposure, suggest that the experience of exposure to ethnic minorities needs to be sufficiently intense to generate a positive effect. The most obvious interpretation of this evidence is that people living closer to the centers become more open to ethnic diversity thanks to personal contact with refugees (Allport, 1954), which can occur, for example, at local stores, in the streets, or while using public transportation. As refugee children are integrated in the Dutch public school system, school-related activities can also foster contact between refugees and natives. Our heterogeneity analysis provides some evidence supporting this mechanism. Indeed, we find that positive treatment effects at the neighborhood level are strongest for panelists below age 55, for panelists who have children living at home, and for women. Given that in the Netherlands a substantial percentage of women work part-time and are more involved in child care than men, these findings are consistent with contact taking place through school-related activities.

Recent work by Alesina, Miano, and Stantcheva (2018) uncovered considerable negatively biased perceptions about facts related to immigrants in an online survey conducted in five Western-European countries and the US. The study shows that providing correct factual information does not shift these perceptions, and that about half of the respondents were not willing to pay anything for receiving information. Confronting respondents with an anecdote about the life of a hard-working immigrant did however reduce the biases. In a similar spirit but different context, Depetris-Chauvin, Durante, and Campante (2020) find that collectively experiencing a national football teams' victory increases interethnic trust and reduces interethnic conflict in sub-Saharan Africa. All in all, these results and ours point to the conclusion that negative perceptions about ethnically different others are hard to shake just by showing people the statistical facts, but may be reduced by first-hand experiences.

Given that prejudices against ethnic minorities are also present in other countries, ${ }^{27}$ it is

\footnotetext{
${ }^{26}$ See also Gehrsitz and Ungerer (2018), who find no effect of increased exposure to asylum seekers at the German county level, but find that at the less-aggregated municipality level support for the anti-immigrant party Alternative für Deutschland (AfD) is somewhat lower in places with larger inflows of asylum seekers.

${ }^{27}$ Heath, Liebig, and Simon (2013) gives an overview of correspondence studies ran across the world and shows that in France, Germany, Italy, the UK, the US and several other countries, job applicants with a minority background have to send many more applications before being invited for a job interview.
} 
reasonable to expect that the effect of exposure of the type we study is similar in other countries. A further indication that our results may be valid outside the Netherlands comes from recent studies that aim at identifying the causal effect of the inflow of minorities on electoral preferences. A general finding is that far-right parties lose popularity in places with a relatively strong presence of minorities who do not just travel through, but are there to stay for at least some time or even permanently (Calderon, Fouka, and Tabellini, 2020; Gehrsitz and Ungerer, 2018; Steinmayr, 2020; Vertier and Viskanic, 2018). Although other factors than immigration issues are taken into account when deciding whom to vote for, these results are consistent with the idea that long-lasting contact with minorities can erode ethnic prejudices.

\section{References}

Albrecht, S. and D. Smerdon (2019). The social capital effects of refugee resettlement.

Alesina, A. and E. La Ferrara (2005). Preferences for redistribution in the land of opportunities. Journal of Public Economics 89(5-6), 897-931.

Alesina, A., A. Miano, and S. Stantcheva (2018). Immigration and redistribution. NBER Working Paper 24733.

Algan, Y., C. Hémet, and D. D. Laitin (2016). The social effects of ethnic diversity at the local level: A natural experiment with exogenous residential allocation. Journal of Political Economy 124(3), 696-733.

Allport, G. W. (1954). The nature of prejudice.

Anwar, S., P. Bayer, and R. Hjalmarsson (2012). The impact of jury race in criminal trials. Quarterly Journal of Economics 127(2), 1017-1055.

Arrow, K. J. (1973). The theory of discrimination. In O. Ashenfelter and A. Rees (Eds.), Discrimination in Labor Markets, pp. 659-661. New Jersey: Princeton University Press.

Ayres, I., M. Banaji, and C. Jolls (2015). Race effects on eBay. RAND Journal of Economics 46(4), 891-917.

Barone, G., A. D'Ignazio, G. de Blasio, and P. Naticchioni (2016). Mr. Rossi, Mr. Hu and politics. The role of immigration in shaping natives' voting behavior. Journal of Public Economics 136, 1-13. 
Bartoš, V., M. Bauer, J. Chytilová, and F. Matějka (2016). Attention discrimination: Theory and field experiments with monitoring information acquisition. American Economic Review 106(6), $1437-75$.

Bertrand, M. and S. Mullainathan (2004). Are Emily and Greg more employable than Lakisha and Jamal? A field experiment on labor market discrimination. American Economic Review 94(4), 991-1013.

Boisjoly, J., G. Duncan, M. Kremer, D. Levy, and J. Eccles (2006). Empathy or antipathy? The impact of diversity. American Economic Review 96(5), 1890-1905.

Calderon, A., V. Fouka, and M. Tabellini (2020). Racial diversity, electoral preferences, and the supply of policy: the Great Migration and civil rights. Harvard Business School Working Paper 20-017.

Card, D., C. Dustmann, and I. Preston (2012). Immigration, wages, and compositional amenities. Journal of the European Economic Association 10(1), 78-119.

Carrell, S. E., M. Hoekstra, and J. E. West (2019). The impact of college diversity on behavior towards minorities. American Economic Journal: Economic Policy 11(4), 159-182.

Cettolin, E. and S. Suetens (2018). Return on trust is lower for immigrants. Economic Journal 129(621), 1992-2009.

Charles, K. K. and J. Guryan (2008). Prejudice and wages: An empirical assessment of becker's the economics of discrimination. Journal of Political Economy 116(5), 773-809.

Chetty, R., J. Friedman, N. Hendren, M. Jones, and S. Porter (2018). The opportunity atlas: Mapping the childhood roots of social mobility. NBER Working Paper 25147.

Corno, L., E. La Ferrara, and J. Burns (2019). Interaction, stereotypes and performance. Evidence from South Africa. IFS Working Papers W19/03.

Dahlberg, M., K. Edmark, and H. Lundqvist (2012). Ethnic diversity and preferences for redistribution. Journal of Political Economy 120(1), 41 - 76.

de la Rica, S., A. Glitz, and F. Ortega (2015). Immigration in Europe: Trends, policies, and empirical evidence. In B. R. Chiswich and P. W. Miller (Eds.), Handbook of the Economics of International Migration, pp. 1303-1362. The Netherlands: Elsevier. 
Depetris-Chauvin, E., R. Durante, and F. Campante (2020). Building nations through shared experiences: Evidence from african football. American Economic Review 110(5), 1572-1602.

Dinas, E., K. Matakos, D. Xefteris, and D. Hangartner (2019). Waking up the Golden Dawn: Does exposure to the refugee crisis increase support for extreme-right parties? Political Analysis $27(2), 244-254$.

Dustmann, C. and I. Preston (2007). Racial and economic factors in attitudes to immigration. B.E. Journal of Economic Analysis \& Policy 7(1), 1-41.

Dustmann, C., K. Vasiljeva, and A. P. Damm (2019). Refugee migration and electoral outcomes. Review of Economic Studies 86(5), 2035-2091.

Edo, A., Y. Giesing, J. Oztunc, and P. Poutvaara (2019). Immigration and electoral support for the far left and the far right. European Economic Review 115, 99-143.

Finseraas, H., T. Hanson, Å. A. Johnsen, A. Kotsadam, and G. Torsvik (2019). Trust, ethnic diversity, and personal contact: A field experiment. Journal of Public Economics 173, 72-84.

Finseraas, H. and A. Kotsadam (2017). Does personal contact with ethnic minorities affect anti-immigrant sentiments? Evidence from a field experiment. European Journal of Political Research 56(3), 703-722.

Gehrsitz, M. and M. Ungerer (2018). Jobs, crime, and votes: A short-run evaluation of the refugee crisis in Germany. ZEW Discussion Papers 16-086.

Halla, M., A. F. Wagner, and J. Zweimueller (2017). Immigration and voting for the far right. Journal of the European Economic Association 15(6), 1341-1385.

Hanson, G. and C. McIntosh (2016). Is the Mediterranean the new Rio Grande? US and EU immigration pressures in the long run. Journal of Economic Perspectives 30(4), 54-82.

Heath, A., T. Liebig, and P. Simon (2013). Discrimination against immigrants - Measurement, incidence and policy instruments. In OECD (Ed.), International Migration Outlook 2013, pp. 191-230. Paris: OECD Publishing.

Hedegaard, M. and J.-R. Tyran (2018). The price of prejudice. American Economic Journal: Applied Economics 10(1), 40-63.

Kling, J. R., J. B. Liebman, and L. F. Katz (2007). Experimental analysis of neighborhood effects. Econometrica 75(1), 83-119. 
List, J. A. (2004). The nature and extent of discrimination in the marketplace: Evidence from the field. Quarterly Journal of Economics 119(1), 49-89.

Ludwig, J., G. J. Duncan, L. A. Gennetian, L. F. Katz, R. C. Kessler, J. R. Kling, and L. Sanbonmatsu (2013). Long-term neighborhood effects on low-income families: Evidence from Moving to Opportunity. American Economic Review 103(3), 226-231.

Merlino, L. P., M. F. Steinhardt, and L. Wren-Lewis (2019). More than just friends? School peers and adult interractial relationships. Journal of Labor Economics 37(3), 663-713.

Ortega, F. and J. G. Polavieja (2012). Labor-market exposure as a determinant of attitudes toward immigration. Labour Economics 19(3), 298-311.

Phelps, E. S. (1972). The statistical theory of racism and sexism. American Economic Review 62(4), 659-661.

Rao, G. (2019). Familiarity does not breed contempt: Generosity, discrimination, and diversity in Delhi schools. American Economic Review 109(3), 774-809.

Schindler, D. and M. Westcott (2020). Shocking racial attitudes: The cultural legacy of black GIs in Europe. Review of Economic Studies, Forthcoming.

Shayo, M. and A. Zussman (2011). Judicial ingroup bias in the shadow of terrorism. Quarterly Journal of Economics 126(3), 1447-1484.

Steinmayr, A. (2020). Contact versus exposure: Refugee presence and voting for the far-right. Review of Economics and Statistics, Forthcoming.

Tabellini, M. (2019). Racial heterogeneity and local government finances: Evidence from the Great Migration. Harvard Business School Working Paper 19-006.

Tabellini, M. (2020). Gifts of the immigrants, woes of the natives: Lessons from the age of mass migration. Review of Economic Studies 87(1), 454-486.

Vasilakis, C. (2018). Massive migration and elections: Evidence from the refugee crisis in Greece. International Migration 56(3), 28-43.

Vertier, P. and M. Viskanic (2018). Dismantling the "jungle": Migrant relocation and extreme voting in France. CESifo Working Paper Series 6927. 


\section{Online Appendix}

\section{A Supplementary tables}

Table A.1: Attitude index by year

\begin{tabular}{lcccccc}
\hline & $N$ & Mean & Min & Max & Median & St. dev. \\
\hline 2011 & & & & & & \\
$\quad$ LISS panel & 5738 & 2.907 & 1.000 & 5.000 & 3.000 & 0.656 \\
$\quad$ Main estimation sample & 4211 & 2.896 & 1.000 & 5.000 & 3.000 & 0.660 \\
$\quad 2012$ & & & & & & \\
$\quad$ LISS panel & 5556 & 2.911 & 1.000 & 5.000 & 3.000 & 0.660 \\
$\quad$ Main estimation sample & 4403 & 2.904 & 1.000 & 5.000 & 3.000 & 0.664 \\
$\quad$ 2013 & & & & & & \\
$\quad$ LISS panel & 5579 & 2.911 & 1.000 & 5.000 & 3.000 & 0.671 \\
$\quad$ Main estimation sample & 4391 & 2.905 & 1.000 & 5.000 & 3.000 & 0.675 \\
$\quad 2015$ & & & & & & \\
$\quad$ LISS panel & 5860 & 2.906 & 1.000 & 5.000 & 3.000 & 0.699 \\
$\quad$ Main estimation sample & 4619 & 2.889 & 1.000 & 5.000 & 3.000 & 0.700 \\
$\quad$ 2016 & & & & & & \\
$\quad$ LISS panel & 5344 & 2.895 & 1.000 & 5.000 & 3.000 & 0.684 \\
$\quad$ Main estimation sample & 4254 & 2.877 & 1.000 & 5.000 & 3.000 & 0.684 \\
$\quad$ Total & & & & & & \\
$\quad$ LISS panel & 28077 & 2.906 & 1.000 & 5.000 & 3.000 & 0.674 \\
$\quad$ Main estimation sample & 21878 & 2.894 & 1.000 & 5.000 & 3.000 & 0.677 \\
\hline
\end{tabular}


Table A.2: Effect of exposure on attitudes, neighborhood

(1)

(2)

(3)

Dep. var:

\begin{tabular}{lcccccc} 
Attitude & Est. (S.E.) & $p$-value & Est. (S.E.) & $p$-value & Est. (S.E.) & $p$-value \\
\hline Exposed & $0.029(0.033)$ & 0.372 & $0.031(0.033)$ & 0.340 & $0.032(0.033)$ & 0.338 \\
Adj. $R^{2}$ & 0.007 & 0.010 & 0.009 &
\end{tabular}

Adj. $R^{2}$

0.007

0.010

0.009

Controls:

Individual

Neighb. / municipal

\# Panelists

5651

$\mathrm{X}$

$X$

\# Data points

21872

5651

$\mathrm{X}$

21872

5651

21872

Notes: Results are reported of linear regressions of Attitude on a binary exposure variable. The variable indicates whether refugees are present within the neighborhood. All specifications include individual fixed effects and year fixed effects. Control variables are listed in Section 3.2.

Table A.3: Effect of exposure on attitudes, municipal
(1)
(2)
(3)

Dep. var:

Attitude

Est. (S.E.)

(1)

Exposed

$-0.013(0.012) \quad 0.285$

Est. (S.E.) $\quad p$-value

$\begin{array}{cc}\text { Est. (S.E.) } & p \text {-value } \\ -0.018(0.013) & 0.186\end{array}$

Adj. $R^{2}$

0.005

0.008

0.008

Controls:

Individual

Neighb. / municipal

\# Panelists

\begin{tabular}{ccc} 
& $X$ & $X$ \\
4968 & 4968 & $X$ \\
19174 & 19174 & 4968 \\
\hline
\end{tabular}

\# Data points

19174

19174

19174

Notes: Results are reported of linear regressions of Attitude on a binary exposure variable. The variable indicates whether refugees are present within the municipality. All specifications include individual fixed effects and year fixed effects. Control variables are listed in Section 3.2.

Table A.4: Effect of exposure on attitudes, municipal w/o neighb.
(1)
(2)
(3)

Dep. var:

\begin{tabular}{lcccccc} 
Attitude & Est. (S.E.) & $p$-value & Est. (S.E.) & $p$-value & Est. (S.E.) & $p$-value \\
\hline Exposed & $-0.020(0.013)$ & 0.128 & $-0.020(0.013)$ & 0.118 & $-0.027(0.014)$ & 0.050 \\
Adj. $R^{2}$ & 0.006 & 0.008 & 0.008 & \\
Controls: & & & $\mathrm{X}$ & $\mathrm{X}$ & \\
Individual & & & & $\mathrm{X}$ & \\
Neighb. / municipal & & & 4948 & 4948 & \\
\# Panelists & 4948 & 18944 & 18944 & \\
\# Data points & 18944 & &
\end{tabular}

Notes: Results are reported of linear regressions of Attitude on a binary exposure variable. The variable indicates whether refugees are present within the municipality excluding the neighborhood. All specifications include individual fixed effects and year fixed effects. Control variables are listed in Section 3.2. 
Table A.5: Effect of duration of exposure on attitudes, neighborhood

(1)

(2)

(3)

Dep. var:

\begin{tabular}{lcccccc} 
Attitude & Est. (S.E.) & $p$-value & Est. (S.E.) & $p$-value & Est. (S.E.) & $p$-value \\
\hline Exposed short & $-0.019(0.050)$ & 0.701 & $-0.016(0.050)$ & 0.753 & $-0.016(0.050)$ & 0.752 \\
Exposed Long & $0.087(0.033)$ & 0.010 & $0.087(0.033)$ & 0.007 & $0.088(0.033)$ & 0.007 \\
Wald test & $-0.106(0.052)$ & 0.041 & $-0.103(0.051)$ & 0.045 & $-0.104(0.051)$ & 0.044 \\
Adj. $R^{2}$ & 0.007 & 0.010 & & 0.010 &
\end{tabular}

Controls:

Individual

Neighb. / municipal

\# Panelists

21872

\begin{tabular}{cc}
$X$ & $X$ \\
& $X$ \\
5651 & 5651 \\
21872 & 21872 \\
\hline
\end{tabular}

\# Data points

21872

21872

Notes: Results are reported of linear regressions of Attitude on categories of duration of exposure within the neighborhood. The baseline category is no exposure. The two exposure categories are Exposed short (six months or less) and Exposed long (more than six months). Also included are results of Wald tests that test whether the two estimated effects are statistically different. All specifications include individual fixed effects and year fixed effects. Control variables are listed in Section 3.2.

Table A.6: Effect of duration of exposure on attitudes, municipal

\begin{tabular}{|c|c|c|c|c|c|c|}
\hline \multirow{2}{*}{$\begin{array}{l}\text { Dep. var.: } \\
\text { Attitude }\end{array}$} & \multicolumn{2}{|l|}{ (1) } & \multicolumn{2}{|l|}{ (2) } & \multicolumn{2}{|l|}{ (3) } \\
\hline & Est. (S.E.) & $p$-value & Est. (S.E.) & $p$-value & Est. (S.E.) & $p$-value \\
\hline Exposed short & $-0.026(0.016)$ & 0.103 & $-0.026(0.016)$ & 0.109 & $-0.029(0.017)$ & 0.095 \\
\hline Exposed Long & $0.000(0.015)$ & 0.998 & $-0.001(0.014)$ & 0.963 & $-0.005(0.015)$ & 0.717 \\
\hline Wald test & $-0.026(0.018)$ & 0.155 & $-0.025(0.018)$ & 0.169 & $-0.024(0.018)$ & 0.185 \\
\hline Adj. $R^{2}$ & 0.005 & & 0.008 & & 0.008 & \\
\hline $\begin{array}{l}\text { Controls: } \\
\text { Individual } \\
\text { Neighb. / municipal } \\
\text { \# Panelists } \\
\text { \# Data points }\end{array}$ & $\begin{array}{c}4968 \\
19174\end{array}$ & & $\begin{array}{c}4968 \\
19174\end{array}$ & & $\begin{array}{c}X \\
X \\
4968 \\
19174\end{array}$ & \\
\hline
\end{tabular}

Notes: Results are reported of linear regressions of Attitude on categories of duration of exposure within the municipality. The baseline category is no exposure. The two exposure categories are Exposed short (six months or less) and Exposed long (more than six months). Also included are results of Wald tests that test whether the two estimated effects are statistically different. All specifications include individual fixed effects and year fixed effects. Control variables are listed in Section 3.2. 
Table A.7: Effect of duration of exposure on attitudes, municipal w/o neighb.

\section{(1)}

(2)

(3)

Dep. var:

\begin{tabular}{lcccccc} 
Attitude & Est. (S.E.) & $p$-value & Est. (S.E.) & $p$-value & Est. (S.E.) & $p$-value \\
\hline Exposed short & $-0.030(0.016)$ & 0.055 & $-0.030(0.016)$ & 0.056 & $-0.036(0.017)$ & 0.036 \\
Exposed Long & $-0.009(0.016)$ & 0.570 & $-0.010(0.016)$ & 0.534 & $-0.017(0.016)$ & 0.279 \\
Wald test & $-0.021(0.019)$ & 0.252 & $-0.021(0.019)$ & 0.266 & $-0.019(0.018)$ & 0.310 \\
Adj. $R^{2}$ & 0.006 & & 0.008 & & 0.008 &
\end{tabular}

Controls:

Individual

Neighb. / municipal

\# Panelists

$x$

$\begin{array}{ccc} & X & X \\ & & X \\ 4948 & 4948 & 4948 \\ 18944 & 18944 & 18944\end{array}$

Notes: Results are reported of linear regressions of Attitude on categories of duration of exposure within the municipality excluding the neighborhood. The baseline category is no exposure. The two exposure categories are Exposed short (six months or less) and Exposed long (more than six months). Also included are results of Wald tests that test whether the two estimated effects are statistically different. All specifications include individual fixed effects and year fixed effects. Control variables are listed in Section 3.2.

Table A.8: Effect of number of refugees on attitudes, neighborhood

\begin{tabular}{|c|c|c|c|c|c|c|}
\hline \multirow[b]{2}{*}{$\begin{array}{l}\text { Dep. var.: } \\
\text { Attitude }\end{array}$} & \multicolumn{2}{|l|}{ (1) } & \multicolumn{2}{|l|}{ (2) } & \multicolumn{2}{|l|}{ (3) } \\
\hline & Est. (S.E.) & $p$-value & Est. (S.E.) & $p$-value & Est. (S.E.) & $p$-value \\
\hline Below 250 & $0.034(0.037)$ & 0.356 & $0.036(0.036)$ & 0.315 & $0.036(0.036)$ & 0.314 \\
\hline Above 250 & $0.023(0.062)$ & 0.709 & $0.025(0.063)$ & 0.690 & $0.026(0.063)$ & 0.686 \\
\hline Wald test & $0.011(0.074)$ & 0.882 & $0.011(0.075)$ & 0.885 & $0.010(0.075)$ & 0.889 \\
\hline Adj. $R^{2}$ & 0.007 & & 0.010 & & 0.009 & \\
\hline $\begin{array}{l}\text { Controls: } \\
\text { Individual } \\
\text { Neighb. / municipal }\end{array}$ & & & $\mathrm{X}$ & & $\begin{array}{l}X \\
X\end{array}$ & \\
\hline \# Panelists & 5651 & & 5651 & & 5651 & \\
\hline \# Data points & 21872 & & 21872 & & 21872 & \\
\hline
\end{tabular}

Notes: Results are reported of linear regressions of Attitude on categories of numbers of refugees within the neighborhood. The baseline category is zero. The two number categories are less than 250 refugees and more than 250 refugees. Also included are results of Wald tests that test whether the two effects are significantly different. All specifications include individual fixed effects and year fixed effects. Control variables are listed in Section 3.2. 
Table A.9: Effect of number of refugees on attitudes, municipal

\section{(1)}

(2)

(3)

\begin{tabular}{|c|c|c|c|c|c|c|}
\hline $\begin{array}{l}\text { Dep. var.: } \\
\text { Attitude }\end{array}$ & Est. (S.E.) & $p$-value & Est. (S.E.) & $p$-value & Est. (S.E.) & $p$-value \\
\hline Below 250 & $-0.027(0.019)$ & 0.161 & $-0.026(0.019)$ & 0.166 & $-0.027(0.019)$ & 0.157 \\
\hline Above 250 & $-0.005(0.013)$ & 0.724 & $-0.005(0.013)$ & 0.687 & $-0.010(0.015)$ & 0.507 \\
\hline Wald test & $-0.022(0.021)$ & 0.288 & $-0.021(0.020)$ & 0.306 & $-0.017(0.021)$ & 0.423 \\
\hline Adj. $R^{2}$ & 0.005 & & 0.008 & & 0.008 & \\
\hline $\begin{array}{l}\text { Controls: } \\
\text { Individual } \\
\text { Neighb. / municipal }\end{array}$ & & & $x$ & & $\begin{array}{l}X \\
X\end{array}$ & \\
\hline \# Panelists & 4968 & & 4968 & & 4968 & \\
\hline \# Data points & 19174 & & 19174 & & 19174 & \\
\hline
\end{tabular}

Notes: Results are reported of linear regressions of Attitude on categories of numbers of refugees within the municipality. The baseline category is zero. The two number categories are less than 250 refugees and more than 250 refugees. Also included are results of Wald tests that test whether the two effects are significantly different. All specifications include individual fixed effects and year fixed effects. Control variables are listed in Section 3.2.

Table A.10: Effect of number of refugees on attitudes, municipal w/o neighb.

(1)

(2)

(3)

Dep. var:

\begin{tabular}{|c|c|c|c|c|c|c|}
\hline Attitude & Est. (S.E.) & $p$-value & Est. (S.E.) & $p$-value & Est. (S.E.) & $p$-value \\
\hline Below 250 & $-0.035(0.020)$ & 0.076 & $-0.035(0.019)$ & 0.076 & $-0.036(0.019)$ & 0.065 \\
\hline Above 250 & $-0.011(0.014)$ & 0.460 & $-0.011(0.014)$ & 0.427 & $-0.019(0.016)$ & 0.217 \\
\hline Wald test & $-0.024(0.022)$ & 0.266 & $-0.023(0.022)$ & 0.279 & $-0.017(0.022)$ & 0.443 \\
\hline Adj. $R^{2}$ & 0.006 & & 0.008 & & 0.008 & \\
\hline $\begin{array}{l}\text { Controls: } \\
\text { Individual } \\
\text { Neighb. / municipal }\end{array}$ & & & $x$ & & $\begin{array}{l}X \\
X\end{array}$ & \\
\hline \# Panelists & 4948 & & 4948 & & 4948 & \\
\hline \# Data points & 18944 & & 18944 & & 18944 & \\
\hline
\end{tabular}

Notes: Results are reported of linear regressions of Attitude on categories of numbers of refugees within the municipality excluding the neighborhood. The baseline category is zero. The two number categories are less than 250 refugees and more than 250 refugees. Also included are results of Wald tests that test whether the two effects are significantly different. All specifications include individual fixed effects and year fixed effects. Control variables are listed in Section 3.2. 
Table A.11: Results of pre-exposure regressions with year dummies, including pre-2011 years

\begin{tabular}{lcccc}
\hline & \multicolumn{2}{c}{ Exposed long } & \multicolumn{2}{c}{ Exposed short } \\
Dep. var.: & Neighborhood & Municipal w/o neighb. \\
Attitude & Est. (S.E.) & $p$-value & Est. (S.E.) & $p$-value \\
\hline 2009 & $-0.047(0.009)$ & 0.000 & $-0.045(0.011)$ & 0.000 \\
2010 & $-0.033(0.011)$ & 0.004 & $-0.033(0.015)$ & 0.031 \\
2011 & $-0.003(0.015)$ & 0.860 & $-0.007(0.017)$ & 0.661 \\
2012 & $0.006(0.018)$ & 0.755 & $0.006(0.020)$ & 0.752 \\
2013 & $0.008(0.022)$ & 0.719 & $0.011(0.024)$ & 0.636 \\
2015 & $-0.031(0.029)$ & 0.300 & $-0.012(0.031)$ & 0.689 \\
2016 & $-0.043(0.034)$ & 0.201 & $-0.032(0.036)$ & 0.376 \\
Treatment group $\times 2009$ & $-0.000(0.054)$ & 0.994 & $-0.017(0.019)$ & 0.387 \\
Treatment group $\times 2010$ & $-0.077(0.069)$ & 0.269 & $-0.023(0.019)$ & 0.232 \\
Treatment group $\times 2011$ & $-0.032(0.044)$ & 0.463 & $-0.009(0.020)$ & 0.652 \\
Treatment group $\times 2012$ & $-0.052(0.058)$ & 0.364 & $0.006(0.022)$ & 0.792 \\
Treatment group $\times 2013$ & $0.018(0.056)$ & 0.746 & $-0.003(0.023)$ & 0.881 \\
Treatment group $\times 2015$ & $-0.009(0.096)$ & 0.929 & $-0.024(0.026)$ & 0.357 \\
\hline Adjusted $R^{2}$ & 0.008 & & 0.009 & \\
\# Panelists & 5581 & & 3688 & \\
\# Data points & 31257 & & 20077 & \\
\hline
\end{tabular}

Notes: Results are reported of linear regressions of Attitude on year fixed effects and interactions between year fixed effects and a dummy referring to the relevant treatment group. Data points come from individuals in the control group or from pre-exposure periods of individuals in the treatment group. All specifications include individuallevel fixed effects and the usual set of individual-, neighborhood-, and municipality-level control variables.

Table A.12: Results of pre-exposure regressions with trend, including pre-2011 years

\begin{tabular}{lccc}
\hline & \multicolumn{2}{c}{ Exposed long } & \multicolumn{2}{c}{ Exposed short } \\
$\begin{array}{l}\text { Dep. var.: } \\
\text { Attitude }\end{array}$ & \multicolumn{2}{c}{ Neighborhood } & Municipal w/o neighb. \\
\hline$t$ & $0.021(0.009)$ & 0.022 & $0.013(0.007) 0.049$ \\
Treatment group $\times t$ & $0.005(0.015)$ & 0.719 & $0.005(0.004) 0.211$ \\
\hline Adjusted $R^{2}$ & 0.004 & 0.004 \\
\# Panelists & 5581 & 3688 \\
\# Data points & 31257 & 20077 \\
\hline
\end{tabular}

Notes: Results are reported of linear regressions of Attitude on a linear time trend and interactions between the trend and a dummy referring to the relevant treatment group. Data points come from individuals in the control group or from pre-exposure periods of individuals in the treatment group. All specifications include individual fixed effects, and the standard set of individual-, neighborhood-, and municipality-level control variables. 
Table A.13: Heterogeneous effects of exposure at municipal level w/o neigh.

\begin{tabular}{|c|c|c|c|c|}
\hline Dep. var.: Attitude & Est. (S.E.) & $p$-value & Est. (S.E.) & $p$-value \\
\hline & \multicolumn{2}{|c|}{ Female } & \multicolumn{2}{|l|}{ Male } \\
\hline Exposed short & $-0.039(0.017)$ & 0.025 & $-0.033(0.028)$ & 0.241 \\
\hline Exposed long & $-0.020(0.018)$ & 0.267 & $-0.015(0.025)$ & 0.540 \\
\hline Adj. $R^{2}$ & 0.007 & & 0.011 & \\
\hline \# Panelists & 2673 & & 2275 & \\
\hline \multirow[t]{2}{*}{ \# Data points } & 10109 & & 8835 & \\
\hline & \multicolumn{2}{|c|}{ With children } & \multicolumn{2}{|c|}{ Without children } \\
\hline Exposed short & $-0.045(0.031)$ & 0.139 & $-0.028(0.017)$ & 0.100 \\
\hline Exposed long & $-0.027(0.028)$ & 0.331 & $-0.010(0.016)$ & 0.560 \\
\hline Adj. $R^{2}$ & 0.006 & & 0.013 & \\
\hline \# Panelists & 2200 & & 2748 & \\
\hline \multirow[t]{2}{*}{ \# Data points } & 8358 & & 10586 & \\
\hline & \multicolumn{2}{|c|}{ Most urbanized } & \multicolumn{2}{|c|}{ Least urbanized } \\
\hline Exposed short & $-0.068(0.023)$ & 0.005 & $-0.032(0.030)$ & 0.284 \\
\hline Exposed long & $-0.030(0.026)$ & 0.264 & $-0.017(0.022)$ & 0.431 \\
\hline Adj. $R^{2}$ & 0.011 & & 0.010 & \\
\hline \# Panelists & 1711 & & 3225 & \\
\hline \multirow[t]{2}{*}{ \# Data points } & 6341 & & 12553 & \\
\hline & \multicolumn{2}{|c|}{ Below median age } & \multicolumn{2}{|c|}{ Above median age } \\
\hline Exposed short & $-0.043(0.023)$ & 0.059 & $-0.029(0.022)$ & 0.188 \\
\hline Exposed long & $-0.017(0.025)$ & 0.498 & $-0.018(0.018)$ & 0.319 \\
\hline Adj. $R^{2}$ & 0.007 & & 0.013 & \\
\hline \# Panelists & 2517 & & 2431 & \\
\hline \# Data points & 8927 & & 10017 & \\
\hline
\end{tabular}

Notes: Results are reported for different subgroups of linear regressions of Attitude on categories of duration of exposure. The baseline category is no exposure. The two exposure categories are Exposed short (six months or less) and Exposed long (more than six months). All specifications include individual and year fixed effects, and the standard set of individual-, neighborhood-, and municipality-level control variables.

Table A.14: Effect of exposure on attitudes for the experimental sample

\begin{tabular}{lcccccc} 
& \multicolumn{2}{c}{$(1)$} & \multicolumn{2}{c}{$(2)$} & \multicolumn{2}{c}{$(3)$} \\
Neighborhood & Municipal & \multicolumn{2}{c}{ Municipal w/o neighb. } \\
Attitude & Est. (S.E.) & $p$-value & Est. (S.E.) & $p$-value & Est. (S.E.) & $p$-value \\
\hline Exposed & $0.129(0.074)$ & 0.080 & $-0.032(0.024)$ & 0.184 & $-0.053(0.022)$ & 0.018 \\
Adjusted $R^{2}$ & 0.023 & 0.028 & 0.031 & \\
\# Panelists & 769 & 636 & 633 & \\
\# Data points & 3407 & 2744 & 2705 & \\
\hline
\end{tabular}

Notes: Results are reported of linear regressions of Attitude on a binary exposure variable. The variable indicates whether refugees are present within the indicated geographical area. All specifications include individual and year fixed effects, and the standard set of individual-, neighborhood-, and municipality-level control variables. 


\section{B Do people move away from neighborhoods with refugees?}

In all previous analyses, the true effects of exposure to ethnic minorities can only be identified in a sample of people who stay in one neighborhood for a sufficiently long time, and this is what our estimations are based on. However, it is important to know whether movements of people are in any way related to experienced or anticipated exposure as this would imply that our findings might only hold for a selected sample. To address this concern, we study whether the decision to move from one neighborhood to another is statistically related to the presence of refugees in the neighborhood. We exploit the month-level structure of the panelists' background variables, including the neighborhood they live in, in combination with the exact month of opening of refugee center to regress a binary variable that indicates whether a panelist has moved on a series of different exposure variables. Given the relatively small number of refugee centers in comparison with the total number of neighborhoods in the Netherlands, the majority of movements that we observe in the data are movements to neighborhoods without a refugee center. We therefore focus on the question whether panelists who have been exposed to refugees in their neighborhood or anticipate that they will be exposed are more likely to move to a neighborhood without refugees than non-exposed panelists.

We construct the dependent and independent variables in the following way. The dependent variable Move $_{t}$ is equal to 1 if in month $t$ the panelist moves to a neighborhood without a refugee center, and equal to 0 if the panelist does not move in that month. We exclude movements to a neighborhood with a refugee center. As independent variables we consider exposure within three, six, or twelve months before moving and in the month of moving, as well as anticipated exposure in the upcoming three or six months. The exposure variables are equal to 1 if refugees have arrived or are about to arrive in the current neighborhood within the specified time frame, and equal to 0 otherwise. The regressions are all based on a linear probability model and include the same set of control variables as in our main analysis and a gender dummy. Regressions further include neighborhood fixed effects and year-month fixed effects. Standard errors are clustered at the neighborhood level. Moreover, we apply the same sample restrictions as in our main analysis regarding individuals who have always been exposed or individuals who experience the closure of a refugee center.

The analysis clearly shows that the decision to move is uncorrelated with exposure, regardless of whether we consider past, present, or anticipated future exposure. The estimated effects of exposure are small and statistically insignificant in all specifications. Results are reported in 
table B.15.

\section{Placebo tests}

We include results of the randomization exercise described in Section 5.4. The figures show distributions of simulated counterfactual treatment estimates and associated $p$-values for placebo regressions in which exposure is defined at the neighborhood level or at the municipal level excluding the neighborhood. Three sets of figures are included, of which each is associated with a different exposure specification (general exposed dummy, exposure lasting shorter/longer than 6 months, below/above 250 refugees). The empirical estimates are depicted as red vertical lines.

Figure C.1: Results of placebo tests - exposed

(a) Neighborhood
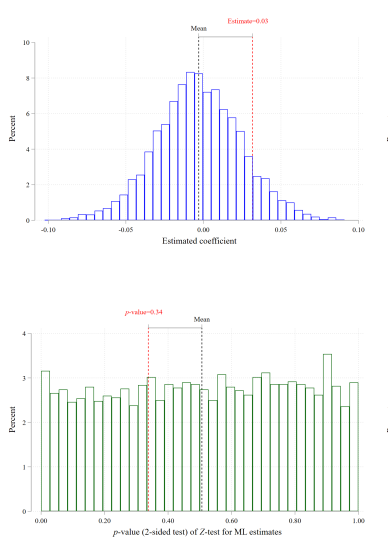

(b) Municipal w/o neighb.
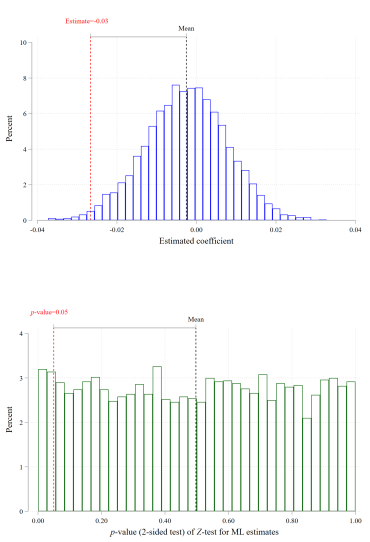

Figure C.2: Results of placebo tests - exposed short and long

(a) Neighborhood

short
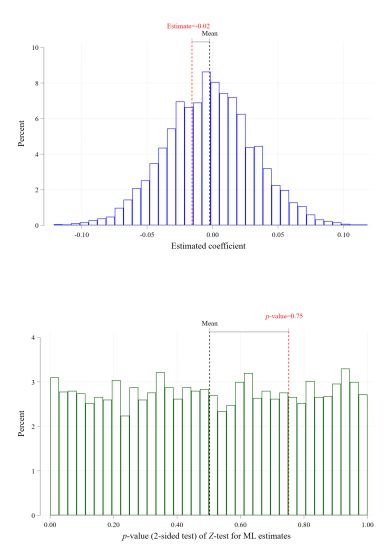

(b) Neighborhood

long
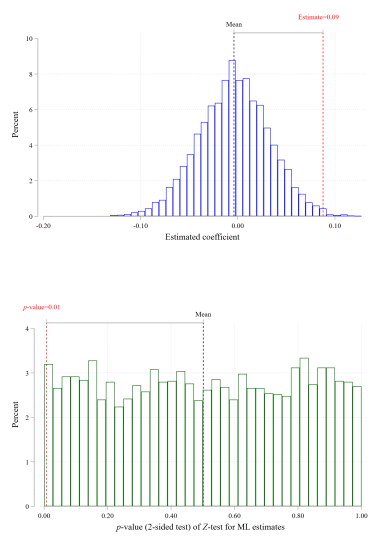

(c) Municipal w/o neighb.

short
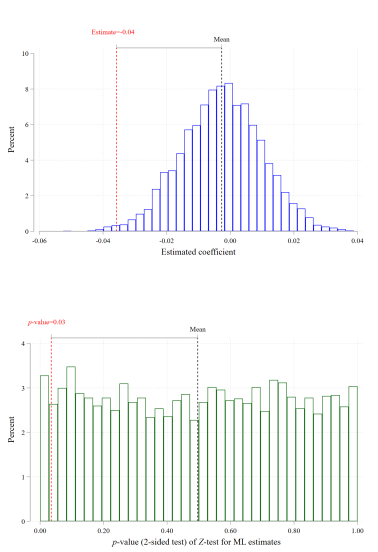

(d) Municipal w/o neighb.

long
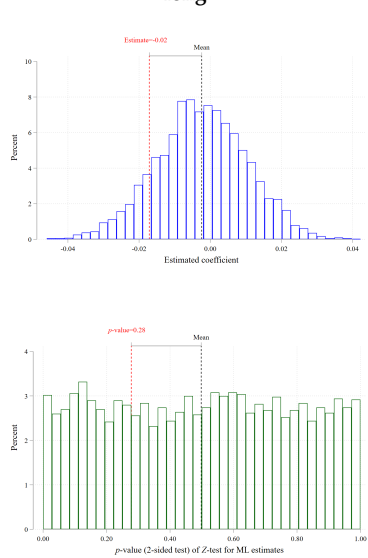
Figure C.3: Results of placebo tests - below and above 250

(a) Neighborhood

below

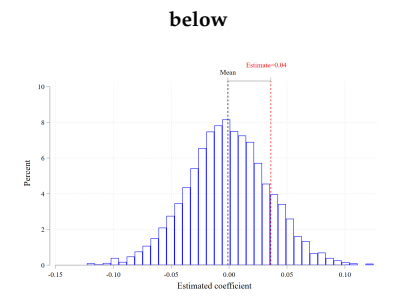

(b) Neighborhood

above

(c) Municipal w/o neighb.

below
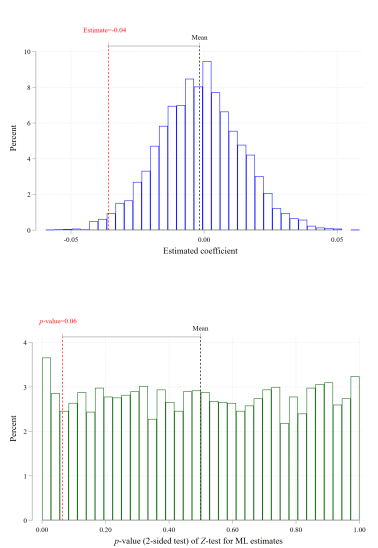

(d) Municipal w/o neighb.

above
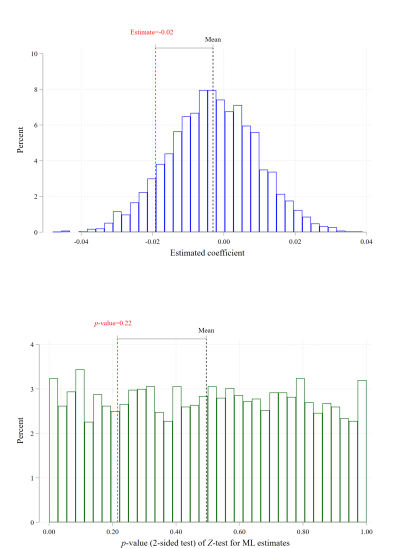

\section{Robustness checks}

\section{D.1 Different duration and number thresholds}

Table D.1: Effect of duration of exposure on attitudes, different duration thresholds

\begin{tabular}{|c|c|c|c|c|c|c|}
\hline \multirow[b]{2}{*}{$\begin{array}{l}\text { Dep. var.: } \\
\text { Attitude }\end{array}$} & \multicolumn{2}{|c|}{$\begin{array}{c}(1) \\
\text { Neighborhood }\end{array}$} & \multicolumn{2}{|c|}{$\begin{array}{c}\text { (2) } \\
\text { Municipal }\end{array}$} & \multicolumn{2}{|c|}{$\begin{array}{c}\text { (3) } \\
\text { Municipal w/o neighb. }\end{array}$} \\
\hline & Est. (S.E.) & $p$-value & Est. (S.E.) & $p$-value & Est. (S.E.) & $p$-value \\
\hline$<5$ months & $-0.015(0.056)$ & 0.790 & $-0.028(0.018)$ & 0.125 & $-0.034(0.018)$ & 0.051 \\
\hline$>5$ months & $0.073(0.031)$ & 0.017 & $-0.008(0.014)$ & 0.584 & $-0.019(0.015)$ & 0.211 \\
\hline Wald test & $-0.088(0.056)$ & 0.114 & $-0.020(0.019)$ & 0.280 & $-0.015(0.019)$ & 0.428 \\
\hline Adj. $R^{2}$ & 0.010 & & 0.008 & & 0.008 & \\
\hline \# panelists & 5651 & & 4968 & & 4948 & \\
\hline \# Data points & 21872 & & 19174 & & 18944 & \\
\hline$<7$ months & $-0.004(0.047)$ & 0.926 & $-0.025(0.017)$ & 0.136 & $-0.032(0.016)$ & 0.050 \\
\hline$>7$ months & $0.084(0.033)$ & 0.011 & $-0.008(0.016)$ & 0.619 & $-0.019(0.017)$ & 0.243 \\
\hline Wald test & $-0.088(0.050)$ & 0.077 & $-0.017(0.019)$ & 0.356 & $-0.013(0.019)$ & 0.497 \\
\hline Adj. $R^{2}$ & 0.010 & & 0.008 & & 0.008 & \\
\hline \# Panelists & 5651 & & 4968 & & 4948 & \\
\hline \# Data points & 21872 & & 19174 & & 18944 & \\
\hline
\end{tabular}

Notes: Results are reported of linear regressions of Attitude on categories of duration of exposure. The baseline category is no exposure. Also included are results of Wald tests that test whether the two estimated effects are statistically different. All specifications include individual and year fixed effects, and the standard set of individual-, neighborhood-, and municipality-level control variables. 
Table D.2: Effect of number of refugees on attitudes, different number thresholds

(1)

Dep. var:

Neighborhood

(2)

Municipal
(3)

Municipal w/o neighb.

\begin{tabular}{|c|c|c|c|c|c|c|}
\hline Attitude & Est. (S.E.) & $p$-value & Est. (S.E.) & $p$-value & Est. (S.E.) & $p$-value \\
\hline Below 200 & $0.040(0.034)$ & 0.244 & $-0.019(0.020)$ & 0.357 & $-0.024(0.020)$ & 0.243 \\
\hline Above 200 & $0.022(0.057)$ & 0.703 & $-0.017(0.015)$ & 0.267 & $-0.028(0.016)$ & 0.079 \\
\hline Wald test & $0.018(0.065)$ & 0.779 & $-0.002(0.023)$ & 0.947 & $0.005(0.024)$ & 0.838 \\
\hline Adj. $R^{2}$ & 0.009 & & 0.008 & & 0.008 & \\
\hline \# panelists & 5651 & & 6738 & & 4948 & \\
\hline \# Data points & 21872 & & 26098 & & 18944 & \\
\hline Below 300 & $0.059(0.040)$ & 0.140 & $-0.023(0.018)$ & 0.190 & $-0.036(0.017)$ & 0.041 \\
\hline Above 300 & $-0.014(0.055)$ & 0.803 & $-0.012(0.016)$ & 0.456 & $-0.017(0.017)$ & 0.305 \\
\hline Wald test & $0.073(0.069)$ & 0.293 & $-0.011(0.020)$ & 0.584 & $-0.018(0.021)$ & 0.377 \\
\hline Adj. $R^{2}$ & 0.010 & & 0.008 & & 0.008 & \\
\hline \# Panelists & 5651 & & 6738 & & 4948 & \\
\hline \# Data points & 21872 & & 26098 & & 18944 & \\
\hline
\end{tabular}

Notes: Results are reported of linear regressions of Attitude on categories of numbers of refugees. The baseline category is zero. Also included are results of Wald tests that test whether the two effects are significantly different. All specifications include individual and year fixed effects, and the standard set of individual-, neighborhood-, and municipality-level control variables.

\section{D.2 Extreme attitudes eliminated}

Table D.3: Effect of exposure to refugees on attitudes, no extreme attitudes

\begin{tabular}{|c|c|c|c|c|c|c|}
\hline \multirow{2}{*}{$\begin{array}{l}\text { Dep. var:: } \\
\text { Attitude }\end{array}$} & \multicolumn{2}{|c|}{$\begin{array}{c}(1) \\
\text { Neighborhood }\end{array}$} & \multicolumn{2}{|c|}{$\begin{array}{c}(2) \\
\text { Municipal }\end{array}$} & \multicolumn{2}{|c|}{$\begin{array}{c}\text { (3) } \\
\text { Municipal w/o neighb. }\end{array}$} \\
\hline & Est. (S.E.) & $p$-value & Est. (S.E.) & $p$-value & Est. (S.E.) & $p$-value \\
\hline Exposed & $0.036(0.033)$ & 0.270 & $-0.013(0.013)$ & 0.330 & $-0.023(0.014)$ & 0.099 \\
\hline $\begin{array}{l}\text { Adj. } R^{2} \\
\text { \# Panelists } \\
\text { \# Data points }\end{array}$ & $\begin{array}{c}0.010 \\
5587 \\
21417\end{array}$ & & $\begin{array}{c}0.008 \\
4914 \\
18799\end{array}$ & & $\begin{array}{c}0.008 \\
4894 \\
18571\end{array}$ & \\
\hline
\end{tabular}


Table D.4: Effect of duration of exposure on attitudes, no extreme attitudes

\begin{tabular}{lcccccc}
\hline & \multicolumn{2}{c}{$(1)$} & \multicolumn{2}{c}{$(2)$} & \multicolumn{2}{c}{$(3)$} \\
Neighborhood & Municipal & \multicolumn{2}{c}{ Municipal w/o neighb. } \\
$\begin{array}{l}\text { Dep. var.: } \\
\text { Attitude }\end{array}$ & Est. (S.E.) & $p$-value & Est. (S.E.) & $p$-value & Est. (S.E.) & $p$-value \\
\hline Exposed short & $-0.010(0.050)$ & 0.843 & $-0.025(0.017)$ & 0.143 & $-0.032(0.016)$ & 0.049 \\
Exposed long & $0.091(0.033)$ & 0.006 & $-0.001(0.015)$ & 0.966 & $-0.013(0.016)$ & 0.430 \\
Wald test & $-0.101(0.051)$ & 0.049 & $-0.024(0.017)$ & 0.159 & $-0.019(0.017)$ & 0.260 \\
Adj. $R^{2}$ & 0.010 & & 0.008 & & 0.009 & \\
\# Panelists & 5587 & 4914 & 4894 & \\
\# Data points & 21417 & 18799 & & 18571 & \\
\hline
\end{tabular}

Notes: Results are reported of linear regressions of Attitude on categories of duration of exposure. The baseline category is no exposure. The two exposure categories are Exposed short (six months or less) and Exposed long (more than six months). Also included are results of Wald tests that test whether the two estimated effects are statistically different. All specifications include individual and year fixed effects, and the standard set of individual, neighborhood-, and municipality-level control variables. On a 5 points scale, attitudes equal to 1 and attitudes larger or equal to 4.5 are considered extreme and are excluded from the analysis.

Table D.5: Effect of number of refugees on attitudes, no extreme attitudes

(1)

Neighborhood
(2)

Municipal
(3)

Municipal w/o neighb.

Dep. var.:

\begin{tabular}{lccrcrc} 
Attitude & Est. (S.E.) & $p$-value & Est. (S.E.) & $p$-value & Est. (S.E.) & $p$-value \\
\hline Below 250 & $0.043(0.034)$ & 0.214 & $-0.021(0.019)$ & 0.270 & $-0.031(0.019)$ & 0.118 \\
Above 250 & $0.027(0.064)$ & 0.671 & $-0.007(0.015)$ & 0.652 & $-0.016(0.015)$ & 0.283 \\
Wald test & $0.015(0.075)$ & 0.837 & $-0.014(0.020)$ & 0.486 & $-0.015(0.021)$ & 0.485 \\
Adj. $R^{2}$ & 0.010 & & 0.008 & 0.008 & \\
\# Panelists & 5587 & 4914 & 4894 & \\
\# Data points & 21423 & 18799 & 18571 &
\end{tabular}

Notes: Results are reported of linear regressions of Attitude on categories of numbers of refugees. The baseline category is zero. The two number categories are less than 250 refugees and more than 250 refugees. Also included are results of Wald tests that test whether the two effects are significantly different. All specifications include individual and year fixed effects, and the standard set of individual-, neighborhood-, and municipality-level control variables. On a 5 points scale, attitudes equal to 1 and attitudes larger or equal to 4.5 are considered extreme and are excluded from the analysis. 


\section{D.3 Largest cities eliminated}

Table D.6: Effect of exposure to refugees on attitudes, no large cities

\begin{tabular}{|c|c|c|c|c|c|c|}
\hline \multirow[b]{2}{*}{$\begin{array}{l}\text { Dep. var.: } \\
\text { Attitude }\end{array}$} & \multicolumn{2}{|c|}{$\begin{array}{c}(1) \\
\text { Neighborhood }\end{array}$} & \multicolumn{2}{|c|}{$\begin{array}{c}(2) \\
\text { Municipal }\end{array}$} & \multicolumn{2}{|c|}{$\begin{array}{c}\text { (3) } \\
\text { Municipal w/o neighb. }\end{array}$} \\
\hline & Est. (S.E.) & $p$-value & Est. (S.E.) & $p$-value & Est. (S.E.) & $p$-value \\
\hline Exposed & $0.031(0.036)$ & 0.397 & $-0.013(0.015)$ & 0.381 & $-0.025(0.015)$ & 0.110 \\
\hline $\begin{array}{l}\text { Adj. } R^{2} \\
\text { \# Panelists } \\
\text { \# Data points }\end{array}$ & $\begin{array}{c}0.010 \\
5196 \\
20250\end{array}$ & & $\begin{array}{c}0.008 \\
4656 \\
18076\end{array}$ & & $\begin{array}{c}0.009 \\
4637 \\
17869\end{array}$ & \\
\hline
\end{tabular}

Notes: Results are reported of linear regressions of Attitude on a binary exposure variable. The variable indicates whether refugees are present within the indicated geographical area. All specifications include individual and year fixed effects, and the standard set of individual-, neighborhood-, and municipality-level control variables. The three most populated cities of the Netherlands, i.e. Amsterdam, Rotterdam and The Hague, are excluded from the analysis.

Table D.7: Effect of duration of exposure on attitudes, no large cities

\begin{tabular}{|c|c|c|c|c|c|c|}
\hline \multirow[b]{2}{*}{$\begin{array}{l}\text { Dep. var.: } \\
\text { Attitude }\end{array}$} & \multicolumn{2}{|c|}{$\begin{array}{c}(1) \\
\text { Neighborhood }\end{array}$} & \multicolumn{2}{|c|}{$\begin{array}{c}(2) \\
\text { Municipal }\end{array}$} & \multicolumn{2}{|c|}{$\begin{array}{c}\text { (3) } \\
\text { Municipal w/o neighb. }\end{array}$} \\
\hline & Est. (S.E.) & $p$-value & Est. (S.E.) & $p$-value & Est. (S.E.) & $p$-value \\
\hline Exposed short & $-0.019(0.057)$ & 0.733 & $-0.022(0.021)$ & 0.288 & $-0.030(0.020)$ & 0.137 \\
\hline Exposed long & $0.080(0.032)$ & 0.014 & $-0.005(0.016)$ & 0.777 & $-0.019(0.017)$ & 0.264 \\
\hline Wald test & $-0.099(0.054)$ & 0.068 & $-0.017(0.021)$ & 0.403 & $-0.011(0.021)$ & 0.619 \\
\hline Adj. $R^{2}$ & \multicolumn{2}{|l|}{0.010} & \multicolumn{2}{|l|}{0.008} & \multicolumn{2}{|l|}{0.009} \\
\hline \# Panelists & \multicolumn{2}{|l|}{5196} & \multicolumn{2}{|l|}{4656} & \multicolumn{2}{|l|}{4637} \\
\hline \# Data points & \multicolumn{2}{|l|}{20250} & \multicolumn{2}{|l|}{18076} & \multicolumn{2}{|l|}{17869} \\
\hline
\end{tabular}

Notes: Results are reported of linear regressions of Attitude on categories of duration of exposure. The baseline category is no exposure. The two exposure categories are Exposed short (six months or less) and Exposed long (more than six months). Also included are results of Wald tests that test whether the two estimated effects are statistically different. All specifications include individual and year fixed effects, and the standard set of individual, neighborhood-, and municipality-level control variables. The three most populated cities of the Netherlands, i.e. Amsterdam, Rotterdam and The Hague, are excluded from the analysis. 
Table D.8: Effect of number of refugees on attitudes, no large cities

(1)

Dep. var:

\begin{tabular}{lcccccc} 
Attitude & Est. (S.E.) & $p$-value & Est. (S.E.) & $p$-value & Est. (S.E.) & $p$-value \\
\hline Below 250 & $0.015(0.038)$ & 0.703 & $-0.024(0.020)$ & 0.235 & $-0.035(0.021)$ & 0.092 \\
Above 250 & $0.051(0.067)$ & 0.444 & $-0.003(0.017)$ & 0.855 & $-0.015(0.017)$ & 0.385 \\
Wald test & $-0.037(0.077)$ & 0.633 & $-0.021(0.021)$ & 0.328 & $-0.021(0.022)$ & 0.350
\end{tabular}

Adj. $R^{2}$

0.010

5196

20250
(2)

Municipal
(3)

Municipal w/o neighb.
\# Panelists

0.008

0.009

\# Data points

4656

4637

18076

17869

Notes: Results are reported of linear regressions of Attitude on categories of numbers of refugees. The baseline category is zero. The two number categories are less than 250 refugees and more than 250 refugees. Also included are results of Wald tests that test whether the two effects are significantly different. All specifications include individual and year fixed effects, and the standard set of individual-, neighborhood-, and municipality-level control variables. The three most populated cities of the Netherlands, i.e. Amsterdam, Rotterdam and The Hague, are excluded from the analysis.

\section{D.4 Largest centers eliminated}

Table D.9: Effect of exposure to refugees on attitudes, no large centers ( $>1000$ refugees)

(1)

Neighborhood
(2)

Municipal
(3)

Municipal w/o neighb.

Dep. var:

\begin{tabular}{lccrccc} 
Attitude & Est. (S.E.) & $p$-value & Est. (S.E.) & $p$-value & Est. (S.E.) & $p$-value \\
\hline Exposed & $0.030(0.034)$ & 0.383 & $-0.018(0.013)$ & 0.175 & $-0.027(0.014)$ & 0.050 \\
Adj. $R^{2}$ & 0.009 & 0.008 & 0.008 & \\
\# Panelists & 5651 & 4968 & 4948 & \\
\# Data points & 21866 & 19168 & 18944 &
\end{tabular}

Notes: Results are reported of linear regressions of Attitude on a binary exposure variable. The variable indicates whether refugees are present within the indicated geographical area. All specifications include individual and year fixed effects, and the standard set of individual-, neighborhood-, and municipality-level control variables. Centers hosting more than 1000 refugees are excluded from the analysis. 
Table D.10: Effect of duration of exposure on attitudes, no large centers ( $>1000$ refugees)

\begin{tabular}{|c|c|c|c|c|c|c|}
\hline \multirow[b]{2}{*}{$\begin{array}{l}\text { Dep. var: } \\
\text { Attitude }\end{array}$} & \multicolumn{2}{|c|}{$\begin{array}{c}(1) \\
\text { Neighborhood }\end{array}$} & \multicolumn{2}{|c|}{$\begin{array}{c}(2) \\
\text { Municipal }\end{array}$} & \multicolumn{2}{|c|}{$\begin{array}{c}\text { (3) } \\
\text { Municipal w/o neighb. }\end{array}$} \\
\hline & Est. (S.E.) & $p$-value & Est. (S.E.) & $p$-value & Est. (S.E.) & $p$-value \\
\hline Exposed short & $-0.021(0.052)$ & 0.683 & $-0.030(0.018)$ & 0.088 & $-0.036(0.017)$ & 0.036 \\
\hline Exposed long & $0.087(0.033)$ & 0.008 & $-0.006(0.015)$ & 0.702 & $-0.017(0.016)$ & 0.279 \\
\hline Wald test & $-0.108(0.053)$ & 0.041 & $-0.025(0.018)$ & 0.177 & $-0.019(0.018)$ & 0.310 \\
\hline $\begin{array}{l}\text { Adj. } R^{2} \\
\text { \# Panelists } \\
\text { \# Data points }\end{array}$ & $\begin{array}{c}0.010 \\
5651 \\
21866\end{array}$ & & $\begin{array}{c}0.008 \\
4968 \\
19168\end{array}$ & & $\begin{array}{c}0.008 \\
4948 \\
18944\end{array}$ & \\
\hline
\end{tabular}

Notes: Results are reported of linear regressions of Attitude on categories of duration of exposure. The baseline category is no exposure. The two exposure categories are Exposed short (six months or less) and Exposed long (more than six months). Also included are results of Wald tests that test whether the two estimated effects are statistically different. All specifications include individual and year fixed effects, and the standard set of individual, neighborhood-, and municipality-level control variables. Centers hosting more than 1000 refugees are excluded from the analysis.

Table D.11: Effect of number of refugees on attitudes, no large centers ( $>1000$ refugees)

(1)

Neighborhood

Dep. var:

\begin{tabular}{lccrcrc} 
Attitude & Est. (S.E.) & $p$-value & Est. (S.E.) & $p$-value & Est. (S.E.) & $p$-value \\
\hline Below 250 & $0.036(0.036)$ & 0.315 & $-0.027(0.019)$ & 0.155 & $-0.036(0.019)$ & 0.065 \\
Above 250 & $0.021(0.069)$ & 0.762 & $-0.011(0.015)$ & 0.480 & $-0.019(0.016)$ & 0.217 \\
Wald test & $0.015(0.079)$ & 0.848 & $-0.016(0.021)$ & 0.441 & $-0.017(0.022)$ & 0.443 \\
Adj. $R^{2}$ & 0.009 & 0.008 & 0.008 & \\
\# Panelists & 5651 & 4968 & 4948 & \\
\# Data points & 21866 & 19168 & 18944 & \\
\hline
\end{tabular}

Notes: Results are reported of linear regressions of Attitude on categories of numbers of refugees. The baseline category is zero. The two number categories are less than 250 refugees and more than 250 refugees. Also included are results of Wald tests that test whether the two effects are significantly different. All specifications include individual and year fixed effects, and the standard set of individual-, neighborhood-, and municipality-level control variables. Centers hosting more than 1000 refugees are excluded from the analysis. 


\section{D.5 Dependent variable based on principal components}

Table D.12: Effect of number of refugees on the first PC of attitudes

\begin{tabular}{|c|c|c|c|c|c|c|}
\hline \multirow[b]{2}{*}{$\begin{array}{l}\text { Dep. var:: } \\
\text { Attitude }\end{array}$} & \multicolumn{2}{|c|}{$\begin{array}{c}(1) \\
\text { Neighborhood }\end{array}$} & \multicolumn{2}{|c|}{$\begin{array}{c}(2) \\
\text { Municipal }\end{array}$} & \multicolumn{2}{|c|}{$\begin{array}{c}\text { (3) } \\
\text { Municipal w/o neighb. }\end{array}$} \\
\hline & Est. (S.E.) & $p$-value & Est. (S.E.) & $p$-value & Est. (S.E.) & $p$-value \\
\hline Exposed & $0.082(0.081)$ & 0.311 & $-0.046(0.033)$ & 0.171 & $-0.067(0.034)$ & 0.049 \\
\hline $\begin{array}{l}\text { Adj. } R^{2} \\
\text { \# Panelists } \\
\text { \# Data points }\end{array}$ & $\begin{array}{c}0.009 \\
5651 \\
21872\end{array}$ & & $\begin{array}{c}0.008 \\
4968 \\
19174\end{array}$ & & $\begin{array}{c}0.008 \\
4948 \\
18944\end{array}$ & \\
\hline
\end{tabular}

Table D.13: Effect of duration of exposure on the first PC of attitudes

(1)

Dep. var.:

Attitude

Exposed short

Exposed long

Wald test

Adj. $R^{2}$

\# Panelists

\# Data points
0.009

5651

21872
(2)

Municipal
(3)

Municipal w/o neighb.
Neighborhood

Est. (S.E.) $\quad p$-value
Est. (S.E.)

$-0.073(0.04$

$-0.016(0.037)$

$-0.057(0.046)$

0.008

4968

19174

0.044

$p$-value
Est. (S.E.) $\quad p$-value

Notes: Results are reported of linear regressions of the first principal component of the attitudes items, on categories of duration of exposure. The baseline category is no exposure. The two exposure categories are Exposed short (six months or less) and Exposed long (more than six months). Also included are results of Wald tests that test whether the two estimated effects are statistically different. All specifications include individual and year fixed effects, and the standard set of individual-, neighborhood-, and municipality-level control variables. 
Table D.14: Effect of number of refugees on the first PC of attitudes

\begin{tabular}{|c|c|c|c|c|c|c|}
\hline \multirow{2}{*}{$\begin{array}{l}\text { Dep. var.: } \\
\text { Attitude }\end{array}$} & \multicolumn{2}{|c|}{$\begin{array}{c}(1) \\
\text { Neighborhood }\end{array}$} & \multicolumn{2}{|c|}{$\begin{array}{c}\text { (2) } \\
\text { Municipal }\end{array}$} & \multicolumn{2}{|c|}{$\begin{array}{c}\text { (3) } \\
\text { Municipal w/o neighb }\end{array}$} \\
\hline & Est. (S.E.) & $p$-value & Est. (S.E.) & $p$-value & Est. (S.E.) & $p$-value \\
\hline Below 250 & $0.096(0.090)$ & 0.291 & $-0.071(0.048)$ & 0.141 & $-0.092(0.049)$ & 0.061 \\
\hline Above 250 & $0.063(0.152)$ & 0.677 & $-0.025(0.038)$ & 0.508 & $-0.048(0.039)$ & 0.227 \\
\hline Wald test & $0.032(0.181)$ & 0.858 & $-0.046(0.054)$ & 0.396 & $-0.044(0.056)$ & 0.425 \\
\hline $\begin{array}{l}\text { Adj. } R^{2} \\
\text { \# Panelists } \\
\text { \# Data points }\end{array}$ & $\begin{array}{r}0.009 \\
5651 \\
21872\end{array}$ & & $\begin{array}{c}0.008 \\
4968 \\
19174\end{array}$ & & $\begin{array}{r}0.008 \\
4948 \\
18944\end{array}$ & \\
\hline
\end{tabular}

Notes: Results are reported of linear regressions of the first principal component of the attitudes items, on categories of numbers of refugees. The baseline category is zero. The two number categories are less than 250 refugees and more than 250 refugees. Also included are results of Wald tests that test whether the two effects are significantly different. All specifications include individual and year fixed effects, and the standard set of individual-, neighborhood-, and municipality-level control variables.

\section{D.6 Individuals with a non-western background excluded}

Table D.15: Effect of exposure to refugees on attitudes, excluding non-westerners

\begin{tabular}{lcccccc}
\hline & \multicolumn{2}{c}{$(1)$} & $c$ & \multicolumn{2}{c}{$(3)$} \\
Neighborhood & Municipal & \multicolumn{2}{c}{ Municipal w/o neighb. } \\
$\begin{array}{l}\text { Dep. var.: } \\
\text { Attitude }\end{array}$ & Est. (S.E.) & $p$-value & Est. (S.E.) & $p$-value & Est. (S.E.) & $p$-value \\
\hline Exposed & $0.033(0.035)$ & 0.344 & $-0.017(0.013)$ & 0.203 & $-0.025(0.013)$ & 0.056 \\
Adj. $R^{2}$ & 0.010 & 0.008 & 0.008 & \\
\# Panelists & 5314 & 4708 & 4691 & \\
\# Data points & 20773 & 18303 & 18090 &
\end{tabular}

Notes: Results are reported of linear regressions of Attitude on a binary exposure variable excluding individuals with a non-Western immigration background (first-or second-generation). The variable indicates whether refugees are present within the indicated geographical area. All specifications include individual and year fixed effects, and the standard set of individual-, neighborhood-, and municipality-level control variables. 
Table D.16: Effect of duration of exposure on attitudes, excluding non-westerners

\begin{tabular}{|c|c|c|c|c|c|c|}
\hline \multirow{2}{*}{$\begin{array}{l}\text { Dep. var.: } \\
\text { Attitude }\end{array}$} & \multicolumn{2}{|c|}{$\begin{array}{c}(1) \\
\text { Neighborhood }\end{array}$} & \multicolumn{2}{|c|}{$\begin{array}{c}\text { (2) } \\
\text { Municipal }\end{array}$} & \multicolumn{2}{|c|}{$\begin{array}{c}\text { (3) } \\
\text { Municipal w/o neighb. }\end{array}$} \\
\hline & Est. (S.E.) & $p$-value & Est. (S.E.) & $p$-value & Est. (S.E.) & $p$-value \\
\hline Exposed short & $-0.002(0.054)$ & 0.977 & $-0.026(0.017)$ & 0.131 & $-0.034(0.017)$ & 0.047 \\
\hline Exposed long & $0.073(0.032)$ & 0.025 & $-0.007(0.014)$ & 0.629 & $-0.017(0.015)$ & 0.264 \\
\hline Wald test & $-0.074(0.055)$ & 0.176 & $-0.019(0.017)$ & 0.269 & $-0.017(0.018)$ & 0.360 \\
\hline Adj. $R^{2}$ & \multicolumn{2}{|l|}{0.010} & \multicolumn{2}{|l|}{0.008} & \multicolumn{2}{|l|}{0.008} \\
\hline \# Panelists & \multicolumn{2}{|c|}{5314} & \multicolumn{2}{|l|}{4708} & \multicolumn{2}{|l|}{4691} \\
\hline \# Data points & \multicolumn{2}{|c|}{20773} & \multicolumn{2}{|l|}{18303} & \multicolumn{2}{|c|}{18090} \\
\hline
\end{tabular}

Notes: Results are reported of linear regressions of Attitude on categories of duration of exposure excluding individuals with a non-Western immigration background (first-or second-generation). The baseline category is no exposure. The two exposure categories are Exposed short (six months or less) and Exposed long (more than six months). Also included are results of Wald tests that test whether the two estimated effects are statistically different. All specifications include individual and year fixed effects, and the standard set of individual-, neighborhood-, and municipality-level control variables.

Table D.17: Effect of number of refugees on attitudes, excluding non-westerners

(1)

Neighborhood
(2)

Municipal
(3)

Municipal w/o neighb.

Dep. var::

\begin{tabular}{lcccccc} 
Attitude & Est. (S.E.) & $p$-value & Est. (S.E.) & $p$-value & Est. (S.E.) & $p$-value \\
\hline Below 250 & $0.019(0.038)$ & 0.605 & $-0.026(0.018)$ & 0.153 & $-0.035(0.019)$ & 0.068 \\
Above 250 & $0.052(0.066)$ & 0.429 & $-0.009(0.015)$ & 0.562 & $-0.018(0.015)$ & 0.238 \\
Wald test & $-0.033(0.075)$ & 0.665 & $-0.018(0.021)$ & 0.392 & $-0.017(0.022)$ & 0.437 \\
Adj. $R^{2}$ & 0.010 & & 0.008 & 0.008 & \\
\# Panelists & 5314 & 4708 & 4691 & \\
\# Data points & 20773 & 18303 & 18090 &
\end{tabular}

Notes: Results are reported of linear regressions of Attitude on categories of numbers of refugees excluding individuals with a non-Western immigration background (first-or second-generation). The baseline category is zero. The two number categories are less than 250 refugees and more than 250 refugees. Also included are results of Wald tests that test whether the two effects are significantly different. All specifications include individual and year fixed effects, and the standard set of individual-, neighborhood-, and municipality-level control variables. 


\section{D.7 Additional controls}

Table D.18: Effect of duration of exposure on attitudes, including municipality-specific time trends

\begin{tabular}{lcccccc}
\hline & \multicolumn{2}{c}{$(1)$} & \multicolumn{2}{c}{$(2)$} & \multicolumn{2}{c}{$(3)$} \\
Neighborhood & Municipal & \multicolumn{2}{c}{ Municipal w/o neighb. } \\
$\begin{array}{l}\text { Dep. var.: } \\
\text { Attitude }\end{array}$ & Est. (S.E.) & $p$-value & Est. (S.E.) & $p$-value & Est. (S.E.) & $p$-value \\
\hline Exposed short & $-0.029(0.047)$ & 0.542 & $-0.025(0.023)$ & 0.260 & $-0.031(0.022)$ & 0.153 \\
Exposed Long & $0.116(0.038)$ & 0.002 & $0.018(0.023)$ & 0.448 & $-0.001(0.024)$ & 0.971 \\
Wald test & $-0.144(0.054)$ & 0.008 & $-0.043(0.017)$ & 0.010 & $-0.030(0.017)$ & 0.078 \\
Adj. $R^{2}$ & 0.028 & & 0.027 & 0.027 & \\
\# Panelists & 5651 & 4968 & 4948 & \\
\# Data points & 21872 & 19174 & 18944 &
\end{tabular}

Notes: Results are reported of linear regressions of Attitude on categories of duration of exposure. The baseline category is no exposure. The two exposure categories are Exposed short (six months or less) and Exposed long (more than six months). Also included are results of Wald tests that test whether the two estimated effects are statistically different. All specifications include individual and year fixed effects, and the standard set of individual, neighborhood-, and municipality-level control variables. In addition, each municipality dummy is interacted with a linear time variable to account for municipality-specific time trends.

Table D.19: Effect of duration of exposure on attitudes, including time trends by urbanization category

(1)

Dep. var:

Attitude

Exposed shor

Exposed Long

Wald test

Adj. $R^{2}$

\# Panelists

\# Data points
(2)

Municipal
(3)

Municipal w/o neighb.

Neighborhood

\begin{tabular}{cccc} 
Est. (S.E.) & $p$-value & Est. (S.E.) & $p$-value \\
\hline $.028(0.018)$ & 0.124 & $-0.036(0.018)$ & 0.046 \\
$.005(0.015)$ & 0.727 & $-0.018(0.016)$ & 0.257 \\
$.023(0.018)$ & 0.201 & $-0.018(0.018)$ & 0.333 \\
0.007 & & 0.008 & \\
4956 & \multicolumn{3}{c}{4936} \\
19124 & \multicolumn{3}{c}{18894}
\end{tabular}

Notes: Results are reported of linear regressions of Attitude on categories of duration of exposure. The baseline category is no exposure. The two exposure categories are Exposed short (six months or less) and Exposed long (more than six months). Also included are results of Wald tests that test whether the two estimated effects are statistically different. All specifications include individual and year fixed effects, and the standard set of individual-, neighborhood-, and municipality-level control variables. In addition, each urbanization category is interacted with a linear time variable to account for time trends specific to differently urbanized areas. 


\section{D.8 Including movers}

Table D.20: Effect of exposure to refugees on attitudes, including movers

\begin{tabular}{lcccccc}
\hline & \multicolumn{2}{c}{$(1)$} & $c(2)$ & \multicolumn{2}{c}{$(3)$} \\
Neighborhood & Municipal & \multicolumn{2}{c}{ Municipal w/o neighb. } \\
Attitude & Est. (S.E.) & $p$-value & Est. (S.E.) & $p$-value & Est. (S.E.) & $p$-value \\
\hline Exposed & $0.013(0.030)$ & 0.666 & $-0.019(0.013)$ & 0.130 & $-0.024(0.013)$ & 0.064 \\
Adj. $R^{2}$ & 0.009 & 0.009 & 0.009 & \\
\# Panelists & 6594 & 5241 & 5221 & \\
\# Data points & 25514 & 20289 & 20058 & \\
\hline
\end{tabular}

Notes: Results are reported of linear regressions of Attitude on a binary exposure variable. The variable indicates whether refugees are present within the indicated geographical area. All specifications include individual and year fixed effects, and the standard set of individual-, neighborhood-, and municipality-level control variables. Panelists who move to another neighborhood are included in the sample and permanently assigned the first postcode with which they appear in the dataset.

Table D.21: Effect of duration of exposure on attitudes, including movers

\begin{tabular}{|c|c|c|c|c|c|c|}
\hline \multirow[b]{2}{*}{$\begin{array}{l}\text { Dep. var.: } \\
\text { Attitude }\end{array}$} & \multicolumn{2}{|c|}{$\begin{array}{c}(1) \\
\text { Neighborhood }\end{array}$} & \multicolumn{2}{|c|}{$\begin{array}{c}(2) \\
\text { Municipal }\end{array}$} & \multicolumn{2}{|c|}{$\begin{array}{c}\text { (3) } \\
\text { Municipal w/o neighb. }\end{array}$} \\
\hline & Est. (S.E.) & $p$-value & Est. (S.E.) & $p$-value & Est. (S.E.) & $p$-value \\
\hline Exposed short & $-0.025(0.044)$ & 0.560 & $-0.033(0.016)$ & 0.049 & $-0.037(0.016)$ & 0.023 \\
\hline Exposed long & $0.060(0.033)$ & 0.069 & $-0.004(0.014)$ & 0.754 & $-0.010(0.015)$ & 0.500 \\
\hline Wald test & $-0.085(0.047)$ & 0.070 & $-0.028(0.017)$ & 0.102 & $-0.027(0.018)$ & 0.127 \\
\hline Adj. $R^{2}$ & \multicolumn{2}{|l|}{0.009} & \multicolumn{2}{|l|}{0.009} & \multicolumn{2}{|l|}{0.009} \\
\hline \# Panelists & \multicolumn{2}{|c|}{6594} & \multicolumn{2}{|l|}{5241} & \multicolumn{2}{|l|}{5221} \\
\hline \# Data points & \multicolumn{2}{|c|}{25514} & \multicolumn{2}{|l|}{20289} & \multicolumn{2}{|l|}{20058} \\
\hline
\end{tabular}

Notes: Results are reported of linear regressions of Attitude on categories of duration of exposure. The baseline category is no exposure. The two exposure categories are Exposed short (six months or less) and Exposed long (more than six months). Also included are results of Wald tests that test whether the two estimated effects are statistically different. All specifications include individual and year fixed effects, and the standard set of individual-, neighborhood-, and municipality-level control variables. Panelists who move to another neighborhood are included in the sample and permanently assigned the first postcode with which they appear in the dataset. 
Table D.22: Effect of number of refugees on attitudes, including movers

\begin{tabular}{|c|c|c|c|c|c|c|}
\hline \multirow[b]{2}{*}{$\begin{array}{l}\text { Dep. var.: } \\
\text { Attitude }\end{array}$} & \multicolumn{2}{|c|}{$\begin{array}{c}(1) \\
\text { Neighborhood }\end{array}$} & \multicolumn{2}{|c|}{$\begin{array}{c}\text { (2) } \\
\text { Municipal }\end{array}$} & \multicolumn{2}{|c|}{$\begin{array}{c}\text { (3) } \\
\text { Municipal w/o neighb. }\end{array}$} \\
\hline & Est. (S.E.) & $p$-value & Est. (S.E.) & $p$-value & Est. (S.E.) & $p$-value \\
\hline Below 250 & $0.029(0.036)$ & 0.414 & $-0.030(0.017)$ & 0.080 & $-0.032(0.018)$ & 0.068 \\
\hline Above 250 & $-0.008(0.054)$ & 0.883 & $-0.010(0.015)$ & 0.496 & $-0.017(0.015)$ & 0.262 \\
\hline Wald test & $0.037(0.066)$ & 0.573 & $-0.020(0.019)$ & 0.303 & $-0.016(0.020)$ & 0.438 \\
\hline Adj. $R^{2}$ & 0.009 & & 0.009 & & 0.009 & \\
\hline \# Panelists & 6594 & & 5241 & & 5221 & \\
\hline \# Data points & 25514 & & 20289 & & 20058 & \\
\hline
\end{tabular}

Notes: Results are reported of linear regressions of Attitude on categories of numbers of refugees. The baseline category is zero. The two number categories are less than 250 refugees and more than 250 refugees. Also included are results of Wald tests that test whether the two effects are significantly different. All specifications include individual and year fixed effects, and the standard set of individual-, neighborhood-, and municipality-level control variables. Panelists who move to another neighborhood are included in the sample and permanently assigned the first postcode with which they appear in the dataset. 


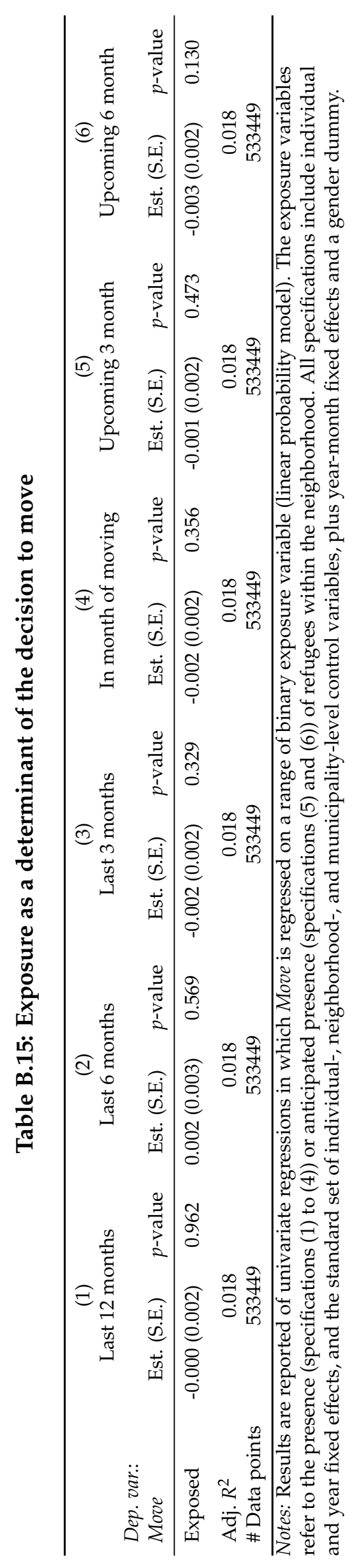




\section{E Procedures in the controlled experiment}

The procedures related to panelists who made choices in the first wave of the experiment (December 2014) are documented in the Online Appendix of Cettolin and Suetens (2018). Sections $\mathrm{B}$ and $\mathrm{C}$ provide a detailed account of the procedures and instructions related to panelists who made choices in the role of trustee, and section F provides a description of the procedures related to panelists in the role of trustor. In all waves, participants made choices in three binary trust games that varied in terms of gains to mutual cooperation, as described in the main text, and the experiment was set up with a focus on choices of participants in the role of trustee. The total number of contacted panelists in the role of trustee was equal to 839 (response of 691) in December 2014, 725 (response of 591) in December 2015 and 1967 (response of 1560) in December 2016.

In the December 2015 and 2016 waves, the instructions related to the description of the experiment, the choice setting and the pay-out rate provided to panelists in the role of trustee were the same as those in the 2014 wave. In the belief elicitation phase, which took place after choice elicitation, a small adjustment was made. Specifically, instead of eliciting all beliefs about the choice of the matched trustor on one computer screen, the beliefs were elicited for each of the three games separately (on three consecutive computer screens).

With respect to the trustors, whose behavior is not relevant for our research but whose choices are needed to match to choices of trustees, the following procedures were followed. In the December 2014 wave a sample was drawn of 382 LISS panelists with a non-Western immigrant background (what we refer to as Minority condition in the main text) and 379 panelists with a native Dutch background (the Majority condition). These panelists were each matched to a trustee, who was communicated the first name of the matched trustor. In the December 2015 wave, the same sample of trustors from the 2014 Minority condition (minus those who had left the panel in the meantime) and a random sample of 390 native Dutch panelists was used to match to the trustees, who were again communicated the first name of the matched trustor. In the December 2016 wave, we adopted a lower-cost strategy and had personnel working at Tilburg University make choices in the role of trustor. We have 28 trustors in the Minority condition and 30 trustors in the Majority condition. Consequently, participants in the role of trustor were matched to multiple trustees. We made sure, however, that the same participant could not be paid out more than once. 